\title{
STARBURST AMACRINE CELLS: MORPHOLOGICAL CONSTANCY AND SYSTEMATIC VARIATION IN THE ANISOTROPIC FIELD OF RABBIT RETINAL NEURONS ${ }^{1}$
}

\author{
EDWARD V. FAMIGLIETTI
}

\author{
Department of Anatomy, Wayne State University School of Medicine, Detroit, Michigan 48201
}

Received August 15, 1983; Revised August 30, 1984; Accepted August 31, 1984

\begin{abstract}
Starburst amacrine cells of rabbit retina have been characterized previously in terms of their highly distinctive and regular dendritic geometry. They have been identified as probable cholinergic neurons of the retina and have been shown to direct output solely to ganglion cells. The objectives of this paper are to chart the variation of starburst amacrine cells across the retina, to register the morphological features which are held constant for individual cells, and to examine factors which may remain invariant for the population with change in retinal position.

Starburst amacrine cells occur as two completely segregated mirror-symmetrical populations, type a and type b cells, separately serving OFF and ON pathways, respectively. They are treated here as two distinct subpopulations with very similar features. A characteristic morphological feature of both types, related to branching pattern and best seen in flat view, is the location of boutons in the distal annular zone. This is the effective zone of synaptic output, which is constant at 50 to $60 \%$ of dendritic field area, regardless of the cell's retinal location. Both type $a$ and type $b$ cells exhibit systematic increase in cell body size and dendritic field diameter, and systematic decrease in frequency of branching and of synaptic boutons with perpendicular distance from the visual streak. These rates of increase or decrease fall off considerably at distances greater than about $1.5 \mathrm{~mm}$ dorsal and ventral to the visual streak, but at this distance, the dendritic field diameters of cells in dorsal retina are about $65 \%$ larger than the diameters of cells in ventral retina.

When type a and type $b$ cells are closely compared, they are seen to differ in several respects. Branching patterns of type a and type $b$ cells differ slightly, the latter being more highly branched, and the normalized branching frequency histograms, characteristic for each type, remain constant with changing retinal position. At the same retinal location type a cells always have larger dendritic field diameters than type $\mathrm{b}$ cells. This difference is significant in ventral retina, out to a distance of at least $4.5 \mathrm{~mm}$ from the streak. The maximum percentage difference in size occurs not at mid-visual streak, but about $1.5 \mathrm{~mm}$ ventral to the streak.

The population statistics of dendritic field overlap and areal dendritic coverage have been calculated using published data on cell densities. It is concluded that overlap is extraordinarily high $(k>25)$, more than 10 times that calculated for retinal ganglion cells. It is also concluded that the area occupied by dendrites, areal dendritic coverage, is more likely to be held constant across the retina than is the overlap of dendritic field perimeters, per se. The function of starburst amacrine cells, as cholinergic neurons modulating the activity of retinal ganglion cells, is discussed in terms of the effective dendritic overlap $\left(k^{*}>12\right)$ of the distal presynaptic zones.
\end{abstract}

Starburst amacrine cells have been identified and characterized in Golgi preparations of rabbit retina as a distinct morphological class of retinal amacrine cells consisting of two types: one with its cell body displaced to the ganglion cell layer and

${ }^{1}$ I thank D. H. McGlone for technical help, and R. M. Miller, D. Wang, and T. Boussie for assistance in developing the computer graphic system. 'This research was supported by National Institutes of Health Grant RO1 EY 03547 to E. V. F. from the National Eye Institute, by Core Center Grant for Vision Research P30 EY 04068, H. Maisel, principal investigator, by a basic research award from Wayne State University, and by an award from the Neuroscience Small Grant Program of Wayne State University. E. V. F. was an Alfred P. Sloan Foundation Fellow in Neuroscience during the initial course of this work. the other with a normally placed cell body (Famiglietti and Siegfried, 1980; Famiglietti, 1981a, b, 1983a). The dendritic branching pattern of starburst amacrine cells may be seen in flat view and encompasses morphological features which gave rise to their descriptive name. These include the radial symmetry of the dendritic tree, its regular dichotomous branching, and the distribution of boutons and varicosities suggestive of synaptic terminals in the distal annular zone of its dendritic tree (Famiglietti, 1983a).

Starburst amacrine cells of rabbit retina are uniquely characterized by their dendritic branching pattern and their mirrorsymmetrical laminar distribution (Famiglietti and Siegfried, 1980; Famiglietti, 1981a, b). The mirror-symmetry of starburst amacrine cells, seen best in vertical sections through the retinal layers, consists in the distribution of cell bodies and of facing 
dendritic trees about a plane which lies near the middle of the inner plexiform layer (IPL). 'I'his plane is the $a / b$ sublaminar border of the IPL, which separates the synaptic connections of $\mathrm{OFF}$ and $\mathrm{ON}$ pathways to ganglion cells (Famiglietti and Kolb, 1976; Famiglietti et al., 1977; Nelson et al., 1978; Famiglietti, 1983b). This geometry of dendritic trees optimally positions starburst amacrine cells to influence OFF and ON pathways selectively in rabbit retina (Bloomfield and Miller, 1981; Famiglietti, 1981a, 1983b). The two features of mirror-symmetry noted here, cell body location and dendritic stratification, form the basis for the correlation of starburst amacrine cells with cholinergic neurons of rabbit retina (Masland and Mills, 1979), as previously described (Famiglietti, 1983a).

The principal subject of this paper is the characterization of starburst amacrine cells as a distinct population of neurons distributed across the retina in the highly anisotropic field of rabbit retinal neurons. This histological anisotropy is typified by the nonuniform distribution of photoreceptors and the cell bodies of ganglion cells, and has been well studied in rabbits and other mammals, including cats and several primates (e.g., Chievitz, 1889; Slonaker, 1897; Davis, 1929; Walls, 1942; Stone, 1965). In cats and primates these familiar anisotropies are more or less radially symmetrical about an area centralis of high ganglion cell density. In rabbit retina, however, density declines with perpendicular distance from the horizontally elongated region of high ganglion cell density, the "visual streak" (IIughes, 1971; Provis, 1979; Oyster et al., 1981).

The decline in density of ganglion cell bodies with distance from the center is accompanied by a systematic increase in the dendritic field size of certain classes of ganglion cell in cat retina (Boycott and Wässle, 1974; Famiglietti and Kolb, 1976) and in rabbit retina (Famiglietti and Siegfried, 1979; E. V. Famiglietti and E. C. Siegfried, unpublished observations). Such inverse variation may be required to ensure that the entire visual field is represented as an uninterrupted mosaic for a given submodality of vision, unless neural elements presynaptic to the ganglion cells can bridge potential gaps in the field. This paper provides evidence that starburst amacrine cells, which have dendritic trees extensive in the plane of the retina and directly presynaptic to select populations of ganglion cells (Famiglietti, 1983b), exhibit systematic regional variation in dendritic field size in the manner of ganglion cells. However, the high degree of dendritic field overlap calculated for starburst amacrine cells raises doubts that their functional role in the organization of the receptive fields of ganglion cells can be explained in simple geometric terms.

\section{Materials and Methods}

Eyes were removed from adult rabbits under Fluothane anesthesia; they were rapidly hemisected, the anterior segment and vitreous humor were removed, and the eyecup was everted in dilute $(0.5$ to $1 \%)$, buffered glutaraldehyde. The retina was then freed from the pigmented epithelium and mounted on a glass slide. After a short period of fixation in more concentrated aldehydes, ranging from 2 to $5 \%$, the retinas were immersed in one of several glutaraldehyde-dichromate mixtures, ranging from 2 to $5 \%$ glutaraldehyde and 2 to $8 \%$ potassium dichromate, for at least 3 days, followed by $1 \%$ silver nitrate for 2 days. Retinas were dehydrated and mounted whole and flat on a slide, either in D.P.X. Mountant or an Epon-Araldite mixture, and were examined in a light microscope with conventional brightfield optics and a Zeiss long-working-distance $\times 100$ Neofluar oil immersion objective (N.A. $=$ 1.0 ), with an estimated depth of focus of $0.4 \mu \mathrm{m}$. Drawings were made with a camera lucida (Zeiss drawing tube) at initial magnifications of $\times 500$ (Fig. $2, A$, and $C$ to $F$ ) or $\times 1000$ (Fig. $2 B$ )

Selection of the sample: Systematic "variation" versus "variability." Material for quantitative analysis of soma and dendritic field size was taken from five retinas of four animals. Since it was necessary to distinguish between "variability" (random variation) and "variation" (systematic variation) in this neuronal population study, a single retina was chosen as the principal source of data (Fig. 1), to minimize the effects of individual variability and of differences in shrinkage which can arise from processing the tissue. The dendritic field and cell body sizes of 55 cells were measured in the right retina of this "brindle" pigmented, adult rabbit (Figs. 1 and 6 to 8). An additional 15 cells were measured in four eyes of three Dutch Belted rabbits (Figs. 7 and 8). The latter were selected for the presence of several overlapping or adjacent type a/type $b$ pairs. Measurements on the cell body sizes of 49 ganglion cells from a sixth retina were available from previous work (Famiglietti and Siegfried, 1979), and as the sizes of morphologically identified ganglion cells at comparable locations matched those from the retina in Figure 1, they were compared to the cell body sizes of type b starburst amacrine cells in the same retinal regions (Fig. 4). Branching analysis was applied to a cell taken from a seventh albino rabbit retina. Although apparent strain differences in cell body size were considerable (Fig. 7), individual variability in dendritic field diameters measured in several retinas proved to be less than expected (Fig. 8). No attempts were made here to make corrections for shrinkage, estimated to be about $30 \%$ on average, nor were attempts made to make such corrections in the work used to calculate dendritic overlap (Masland, 1980; Vaney et al., 1981).

Measurement and graphic reconstruction of starburst amacrine cells. Cell body diameters were measured under oil immersion, using a $\times 100$ objective (resolution about $0.25 \mu \mathrm{m}$ in the plane of the stage) and an eyepiece graticule inscribed with concentric circles spaced $2.4 \mu \mathrm{m}$ apart at this magnification. Visual interpolation could be made between lines to the nearest $0.5 \mu \mathrm{m}$. The largest diameter (major axis) was found, and then a second measurement was made along a minor axis perpendicular to the major axis, and the average value was taken. Dendritic field diameters were measured in similar fashion, using a $\times 16$ or a $\times$ 25 objective lens (circles spaced 15.3 and $9.6 \mu \mathrm{m}$ apart, respectively) with interpolation to the nearest $5 \mu \mathrm{m}$; four to six radial measurements were made and the average value was doubled.

Computer graphic images (Figs. 9 and 11) were prepared on a system developed by E. V. F. at Wayne State University. This interactive system was built around a microscope with stepping motor-controlled stage and focus controls (cf. Wann et al., 1973), as well as a drawing tube and a digitizing tablet, and it allows points along the dendritic tree and branching logic to be logged into computer memory in threedimensional Cartesian coordinates with an accuracy conservatively estimated at $0.8 \mu \mathrm{m}$. The dendrites of typical cells were logged at average intervals of $2 \mu \mathrm{m}$, and computer programs operating on these data enabled certain global statistics to be extracted for these dendritic trees.

Some starburst amacrine cells in these preparations were clearly incompletely impregnated. Complete failure to impregnate their fine processes using other Golgi methods explains why they were not previously characterized. If some of the cells in this study were not as radially symmetrical as assumed (if for example the cell in Fig. $2 A$ were actually completely impregnated), and if such asymmetry were common, then values for dendritic coverage and overlap (cf. Fig. 10 and Table II) would have to he revised downward. There is every reason to believe, however, that the most radially symmetrical dendritic trees are typical (e.g., Figs. $2 B$ and $9 A$ ), since they are common in the best Golgi preparations.

Establishment of a reference system for retinal topography. The vertical midpoint of the visual streak was determined in each retina at several locations along its horizontal course. Density of ganglion cells was the chief criterion used, and density was assessed by viewing the refractile images of the unstained cell bodies. Information on cell body and dendritic field size of ganglion cells in the region was also used when available. The dorsal and ventral margins of the visual streak were determined by inspection as regions where the closely packed cells of uniform size give way to clusters of cells and where the first conspicuously larger ganglion cell bodies are found. A line halfway between these margins, which were typically about $600 \mu \mathrm{m}$ apart, was designated the mid-visual streak, determined with an estimated accuracy of $50 \mu \mathrm{m}$. Measurements of distance on the retina were made in most cases using an eyepiece graticule with divisions $95 \mu \mathrm{m}$ apart and interpolating to the nearest $50 \mu \mathrm{m}$ along a perpendicular connecting the cell body to the visual streak. Camera lucida drawings of the retinas were also made in each case, and "great circle" distances on the flat mounted retina were calculated when necessary by summing measurements along line segments drawn from the visual streak and cell body to incisures made to flatten the retina. The modest errors inherent in 
Figure 1. Golgi-impregnated treal surface up. This retina is the primary source of data for this study (see "Materials and Methods"). Circles are centered upon retinal locations of starburst amacrine cells. Sizes of the circles are roughly scaled to average dendritic field perimeters. The optic disc was cut away (central irregular outline), and the mid-visual rowheads). Arrows indicate locations of cells depicted in Figure 2. $D$, dorsal; $V$, ventral; $N$, nasal; $T$, rabbit retina, flat mounted, vistreak is drawn as a thin line (artemporal. Scale bar $=5 \mathrm{~mm}$.

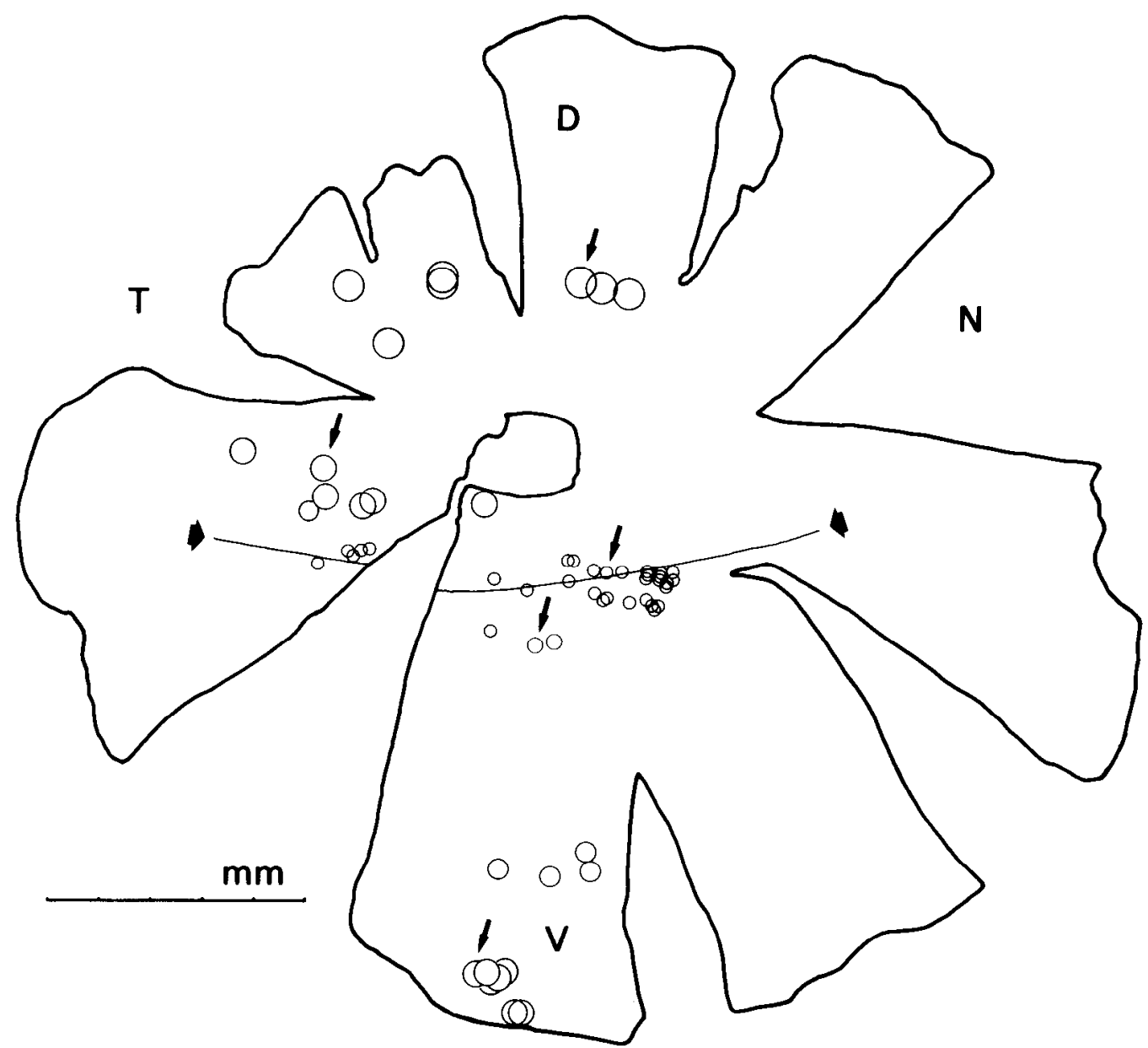

these methods were minimized by selecting cells near a single central perpendicular drawn through the visual streak and optic disc.

The dimensional data obtained from starburst amacrine cells in the retina of Figure 1, and presented in Figures 7 and 8, were also plotted with reference to a single point on the retinal surface, the center of the visual streak (not illustrated). Plotted thus, however, the data on dendritic field diameter showed much more scatter than that exhibited when plotted with respect to perpendicular distance from the linear visual streak, as in Figure 8.

\section{Results}

Morphological characterization of starburst amacrine cells. Representative examples of starburst amacrine cells are depicted in the camera lucida drawings of Figure 2. They are notable for the range of variation in size and general appearance. All but one of these examples (Fig. $2 C$ ) are located in the retina of Figure 1 (arrows), where they are found at intervals along the dorsoventral axis of the retina. All but one (Fig. 2B) lie close to a straight line passing through the optic disc and perpendicular to the visual streak. They range from $5.6 \mathrm{~mm}$ dorsal $(d=-5.6)$ to $7.4 \mathrm{~mm}$ ventral $(d=7.4)$ to the visual streak (Fig. 2, $A$ and $F$, respectively), and one example is taken from the mid-visual streak (Fig. $D$ ). Two are type b cells (Fig. $2, A$ and $D$ ), and the remainder are type a cells. Although the range of variation cell body diameter is small, the range in dendritic field diameter is large.

The type a starburst amacrine cell of Figure $2 B$ is one of the most completely impregnated of this group and is more accurately represented in terms of dendritic taper and relative thickness, since it was initially drawn at twice the magnification of the other six cells. In this instance, the three concentric, annular dendritic zones are evident (Famiglietti, 1983a): (1) a "proximal zone," about $100 \mu \mathrm{m}$ in diameter, of conventionally tapering dendrites, (2) an "intermediate zone," about $300 \mu \mathrm{m}$ in (outer) diameter, consisting of uniformly thin (about $0.2 \mu \mathrm{m}$ ) dendrites, and (3) a "distal zone," about $500 \mu \mathrm{m}$ in outer diameter, which bears varicosities, boutons en passant, and boutons terminaux, averaging about $1 \mu \mathrm{m}$ in diameter.

The frequency of boutons per unit dendritic length in the distal zone varies greatly among starburst amacrine cells. As can be seen in Figure 2, this variation is systematic; the highest frequency occurs in the visual streak (Fig. $2 D$ ), whereas the lowest frequency is found in dorsal peripheral retina (Fig. 2A). Other features which change systematically, but which have not been extensively analyzed, are absolute frequency of dendritic branching and dendritic density per unit area, both of which fall off with distance from the visual streak.

Starburst amacrine cells of the ganglion cell layer. In a large sample exceeding 100 cells, normally placed starburst amacrine cells were observed without exception to branch in sublamina a of the IPL, whereas starburst cells with their cell bodies displaced to the ganglion cell layer all branched in sublamina b. This is the basis for their designations as "type a" and "type b" cells (Famiglietti and Siegfried, 1980; Famiglietti, 1981a, 1983a). Figure 3 illustrates several type b cells which lie in the visual streak of the retina of Figure 1 . A cluster of three type $b$ starburst anacrine cells, accompanied by a ganglion cell with a "small-to-medium-size" cell body, is shown at two different focal planes to illustrate their dendritic branching and dendritic field overlap (Fig. $3 c$ ), and their cell bodies in the ganglion cell layer (Fig. $3 b$ ) of this flat mounted retina. In this preparation, the finest axons of the smallest ganglion cells are impregnated in virtually all cases. This is illustrated in the case of a "small tufted" ganglion cell in the micrograph of Figure $3 a$, which includes the cell bodies of two type $b$ starburst amacrine cells 


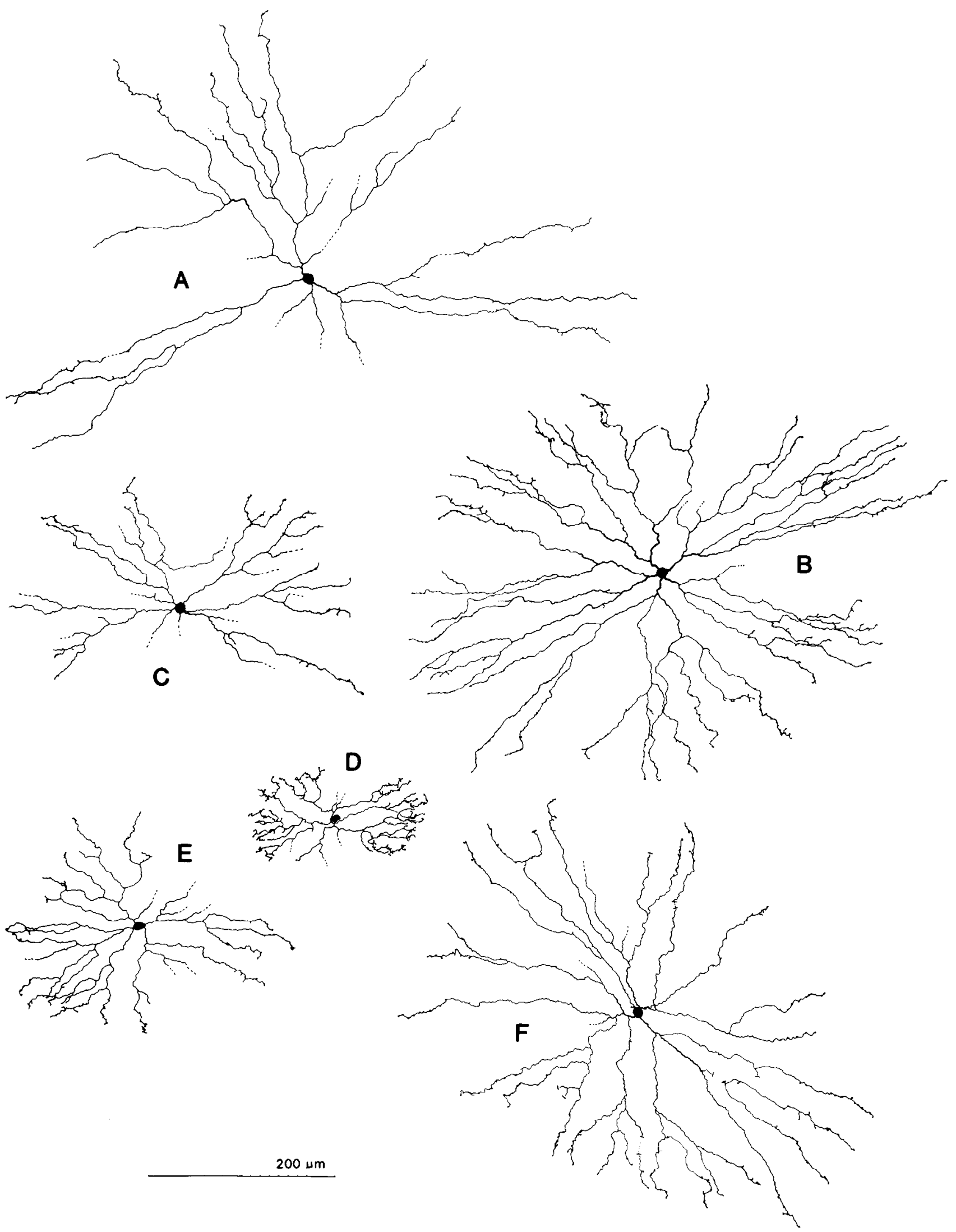

Figure 2. Morphological constancy and systematic variation across the retina in the dendritic morphology of starburst amacrine cells. All cells are from the retina of Figure 1, except $C$, which is from the left eye of the same animal. Included are type a cells $(B, C, E$, and $F)$ and type b cells $(A$ and $D$ ). Some cells are incompletely impregnated (dashed line extensions of dendrites), and in some instances dendrites could not be followed due to dense impregnation (hash marks interrupting dendrites). Retinal distances are: $d=-5.6,-1.65,-0.75,0.0,1.1$, and 7.4 mm, $A$ through $F$, respectively. To permit reproduction at low magnification, the thinnest dendrites are at least 3 times their actual diameter, and boutons are 1.5 to 2 times their actual size. Calibration $=200 \mu \mathrm{m}$ in $10-\mu \mathrm{m}$ intervals. 


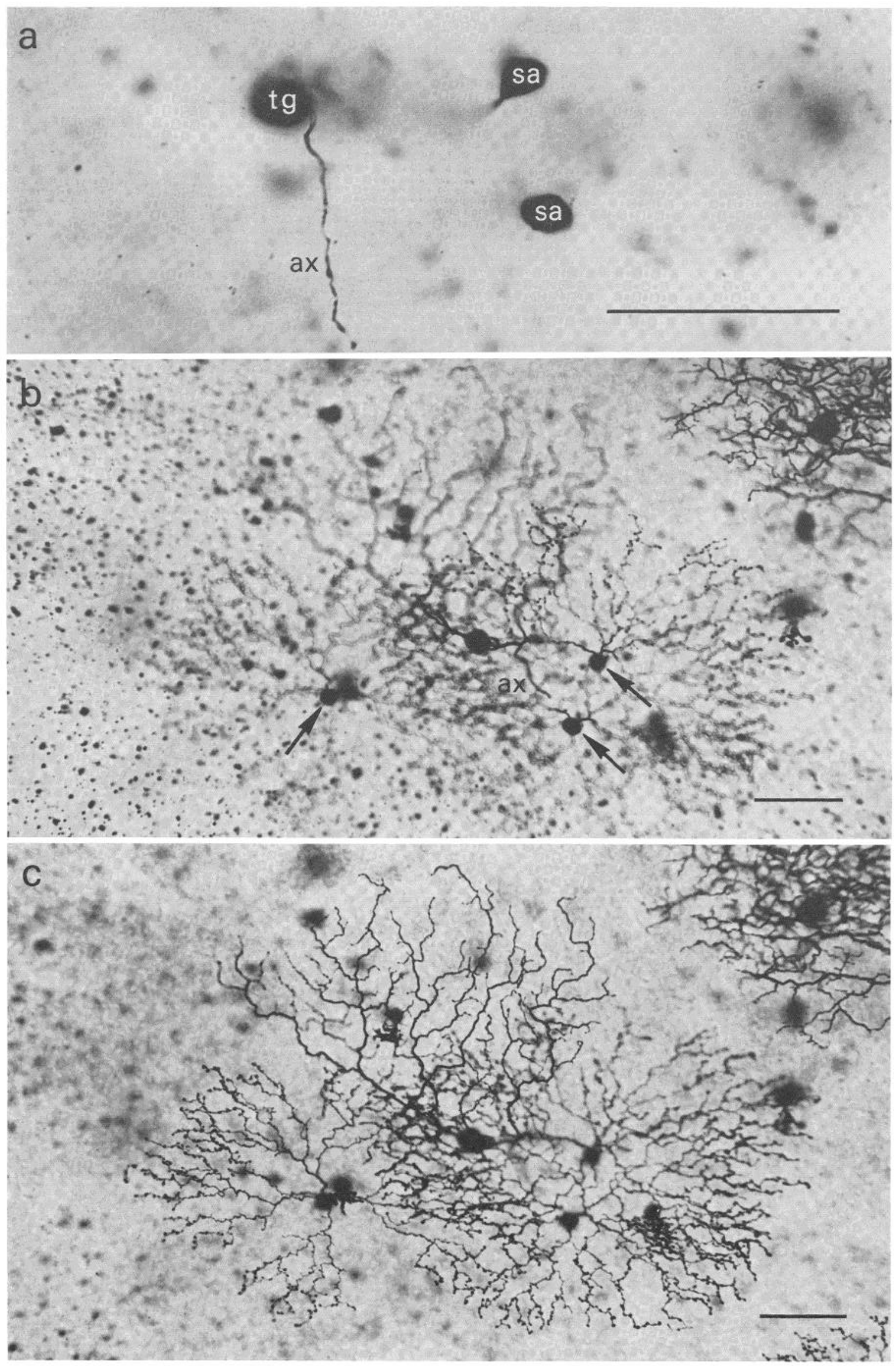


(Fig. $3 a, s a$ ). The fine axon (Fig. $3 a, a x$ ) is impregnated to a length of $60 \mu \mathrm{m}$, but in all Golgi preparations of adult rabbit retina thus far examined, such processes were never seen to emerge from the displaced cell bodies of type b starburst amacrine cells.

When the cell body sizes of type b starburst amacrine cells and the smallest ganglion cells are compared at corresponding retinal locations, they are found to constitute significantly different populations. In Figure 4, a comparison is made of cell body sizes of 37 starburst amacrine cells from the retina of Figure 1, and 49 ganglion cells of five major classes from a second well matched retina (see "Materials and Methods"). All of the cells lie near to or in the visual streak. It is clear that the distribution of soma sizes for starburst amacrine cells (Fig. $4, a$ and $b$ ) only partly overlaps that of ganglion cells at the low end of their distribution (Fig. 4, $c$ and $d$ ). In a comparison of the type $\mathrm{b}$ starburst amacrine cells (Fig. $4 b$ ) with the smallest group of "tufted" ganglion cells (Fig. 4c), the two distributions have mean values of $9.3 \pm 0.5$ and $10.8 \pm 0.7 \mu \mathrm{m}$, respectively, and the means are significantly different $\left(t_{33 d f}=7.3, p<0.001\right)$. This is further evidence substantiating the view that starburst

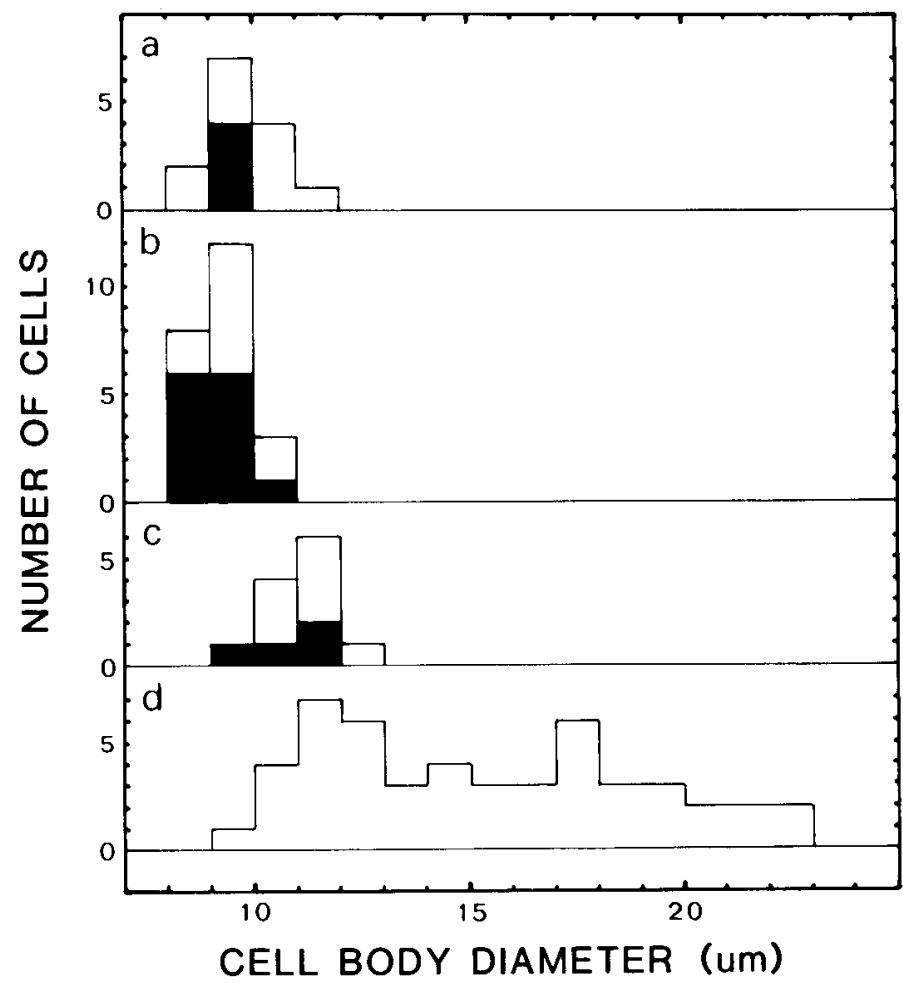

Figure 4. Histograms of cell body size: A comparison of diameters of starburst amacrine cells and ganglion cells. Fourteen type a $(a)$ and 23 type $b(b)$ starburst amacrine cells are compared with the 12 smallest (tufted) ganglion cells (c) extracted from a sample of 49 ganglion cells of five major classes $(d)$. The samples include cells in the visual streak (solid bars) and cells just below the streak (open bars). The statistical difference between type $\mathrm{b}$ (displaced) starburst amacrine cells $(b)$ and the smallest (tufted) ganglion cells (c) is highly significant, but differences between type a (normally placed) and type b starburst amacrine cells are not significant (see the text). amacrine cells, in particular type b cells, are amacrine cells and not ganglion cells.

Additional evidence that starburst amacrine cells are indeed amacrine cells is provided in studies showing that cells in the ganglion cell layer which synthesize acetylcholine do not label with dyes which are instilled in the optic nerve for retrograde transport into ganglion cell bodies (Hayden et al., 1980). Finally, electron microscopic study of starburst amacrine cells reveals that they are presynaptic to other neurons (Famiglietti, $1983 \mathrm{~b}$ ), whereas ganglion cells are not known to have presynaptic dendrites.

Morphological constancy of starburst amacrine cells. Quantitative variation in morphological parameters of starburst amacrine cells, such as dendritic field diameter, and frequency of branching and boutons has been noted above. In contrast, other relative measurements of these cells remain fairly constant across the retina. Prominent among these constant features are those related to dendritic branching pattern. One of these measures is that of the fractional area of the whole dendritic field constituted by the distal annular zone of boutons, which comprises 50 to $60 \%$ of the dendritic field area, regardless of retinal location.

A second, relatively constant feature is described in a histogram which relates branching frequency to dendritic branching order (e.g., primary, secondary dendrites, etc.). The use of branching order as the independent variable serves to establish "bin width" in a graph of the variation of branching frequency as a function of somatofugal distance. Since such a graph ignores dendritic branch (or "segment") length, it serves to normalize data from cells of different dendritic field diameters (Fig. 5). Branching distributions of this kind usually have a single peak of maximum branching frequency. It is the location of this peak, however, its narrowness, and the particular skewing of the frequency distribution, that can help to distinguish among morphological cell types.

For comparison, histograms of two class I ganglion cells from rabbit retina (Fig. 5, $e$ and $f$ ) are shown at the same scale as four starburst amacrine cells (Fig. 5, $a$ to $d$ ). The class I ganglion cells are apparent homologues of class I or alpha cells in cat retina (Boycott and Wässle, 1974; Famiglietti and Kolb, 1976; Famiglietti and Siegfried, 1979) and share with starburst amacrine cells a radially symmetrical and dichotomous branching pattern which is relatively regular and nonoverlapping in the plane of branching. Their branching pattern is "radiate," however (Famiglietti and Kolb, 1976), a term which signifies a decreasing frequency of branching with radial distance from the soma (Ramón-Molincr, 1962), and a pattern reflected in the leftward skewing of the branching frequency distributions of Figure $5, e$ and $f$. In contrast, the distributions of four starburst amacrine cells are skewed to the right (Figs. 5, $a$ to $d)$, reflecting a "tufted" branching pattern or an "increased frequency of branching with distance from the soma." In the small sample of starburst amacrine cells analyzed here, the rightward skewing as well as the total number of branches is relatively independent of retinal location and of average dendritic field diameter, which ranges here from 200 to $520 \mu \mathrm{m}$.

Homogeneity of starburst amacrine cells. The homogeneity of starburst amacrine cells could be tested by examining any subset, $N$, of significant morphological parameters for clustering of values when graphed in $N$-dimensional space. Two

Figure 3. Starburst amacrine cells of the ganglion cell layer. Golgi-impregnated, type b, "displaced" starburst amacrine cells and ganglion cells in the visual streak of the flat mounted rabbit retina of Figure 1. $a$, Focus on the ganglion cell layer. Two cell bodies of type $b$ starburst amacrine cells $(s a)$ are smaller than the body of a "tufted" ganglion cell $(t g)$ with its axon $(a x)$ : among the smallest ganglion cells of rabbit retina. $b$, Three overlapping type b starburst amacrines. Their cell bodies (arrows) are in the same plane as the cell body of a "medium-size" ganglion cell. $c$, Focus on the dendritic trees of the cells in $b$. Boutons en passant and boutons terminaux in the distal annular dendritic zone are at the highest frequency per unit length in such type b cells of the visual streak. Note the tendency to fasciculation of distal dendrites in regions of overlap. Calibration $=50 \mu \mathrm{m}$. 


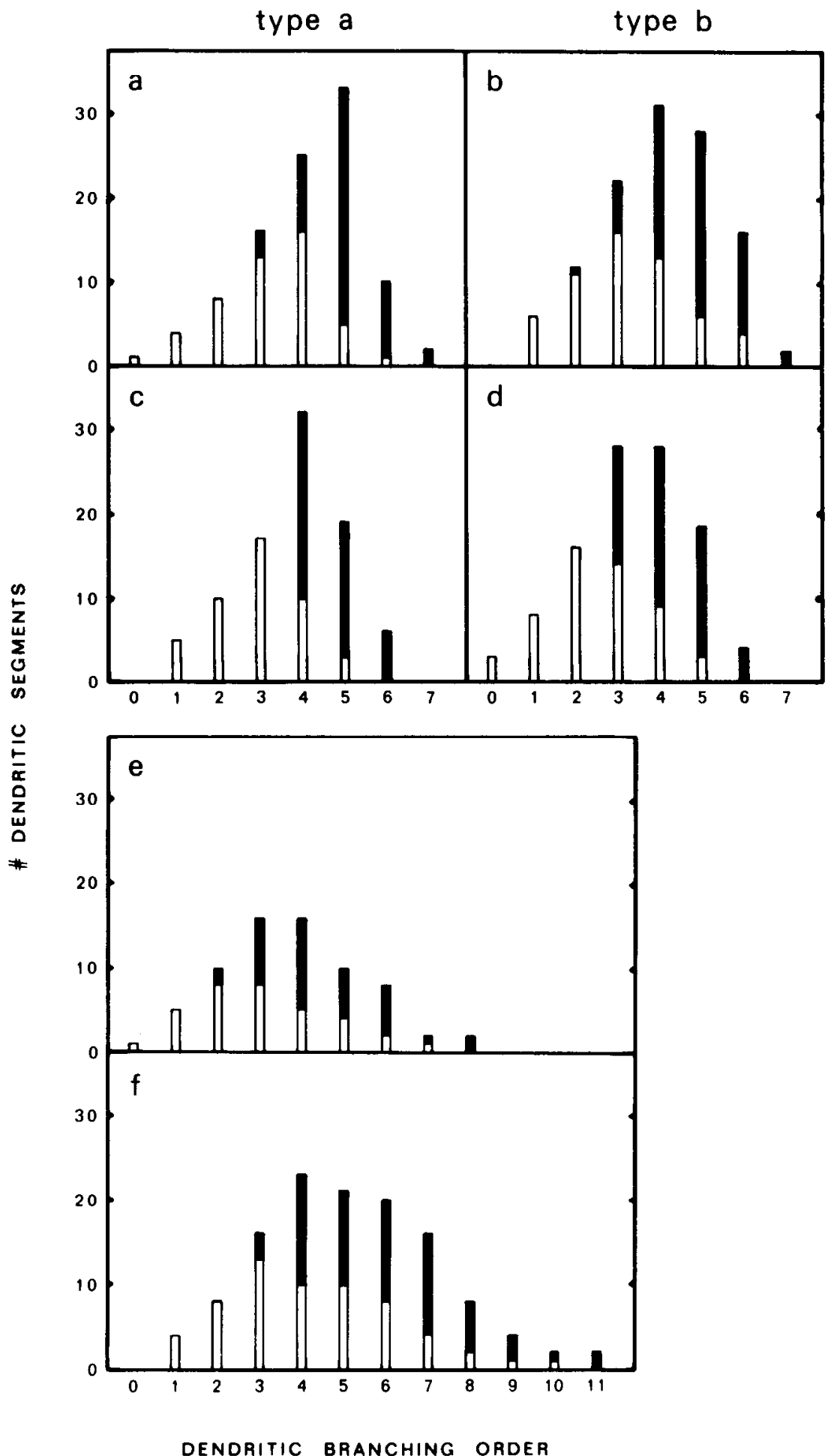

Figure 5. Dendritic branching analysis: Segmental branching frequency distributions of starburst amacrine cells $(a$ to $d)$ and class I ganglion cells ( $e$ and $f$ ). Preterminal (white bars) and terminal branch segments (black bars) are counted separately. The distributions of starburst amacrine cells and those of the ganglion cells are skewed in opposite directions, and the shapes of the distributions are relatively independent of dendritic field size and retinal location where examined (see the text). Cells with less than five primary dendrites usually exhibit secondary branching very close to the cell body in order to generate a radially symmetrical pattern. Thus, for comparison with more regular trees, the short primary branches of these individual dendritic systems are "zero order," the secondary branches are "first order," etc. $a$, Type a cell of Figure $9 ; b$, type b cell of Figure $9 ; c$, type a cell of Figure $2 B ; d$, type b cell of Figure $2 A$ in Famiglietti (1983a), $0.35 \mathrm{~mm}$ dorsal to streak; $e$ and $f$, class I type a ganglion cells, 0.2 and $1.8 \mathrm{~mm}$ ventral to streak.

parameters, cell body size and dendritic field diameter, have been selected here for several reasons. They are readily measured, easily displayed in a two-dimensional medium, commonly evaluated in studies of retina, and illustrate the importance of information on retinal position in characterizing neurons of the inner retina, as Boycott and Wässle (1974), Famiglietti and Kolb (1976), and others have demonstrated for retinal ganglion cells.

In examining the question of homogeneity, two issues are addressed: (1) the similarity of type a and type b cells to each other, and (2) the similarity of cells taken from neighboring locations and even from different retinal regions. The param- eter of cell body size has been analyzed separately in Figure 4, where type a and type b cells have been compared in the streak and just outside the streak (near-streak). The small differences in the calculated mean values are not statistically significant at either location $\left(t_{15 \text { df }}=0.89, p<0.4\right.$; and $t_{18 \text { df }}=1.27,0.2<p$ $<0.3$ ). If type a and type b cells are pooled, there is no significant difference in cell body size, when cells in the streak are compared with cells just outside the streak.

Both cell body and dendritic field size are examined in the two-parameter graph of Figure 6, which displays data from the single retina of Figure 1. Type a cells are distinguished from type $b$ cells, and cells in dorsal retina are marked differently 


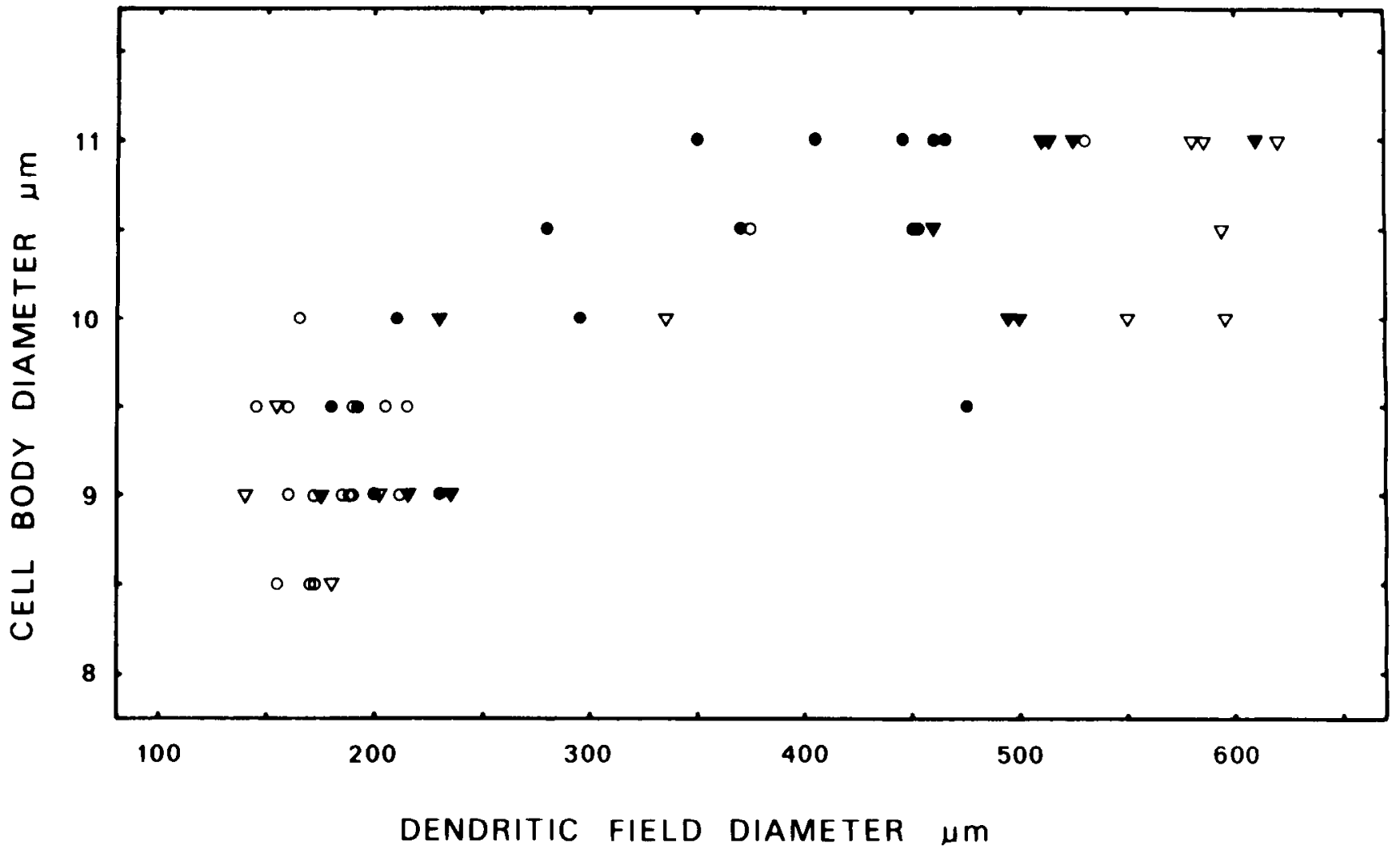

Figure 6. Cell body versus dendritic field diameter of starburst amacrine cells from the retina of Figure 1. Circles represent cells from ventral retina and inverted triangles represent dorsal cells. Solid symbols are type a cells and open symbols are type b cells. Quantitative differences between type a and type b cells are not revealed here without representation of precise topographic data.

from cells in ventral retina, but precise topographic location, which varies over a $13.8-\mathrm{mm}$ range dorsal and ventral to the visual streak, is not represented in this graph. No obvious differences between type a and type b cells can be discerned here. In the pooled sample, however, there is a significant positive correlation between the two parameters of cell body size and dendritic field size. This is reflected in the high correlation coefficient ( $R=0.81$ ) obtained when a straight line of positive slope is fitted to the data obtained from these 55 cells.

The goodness of fit to a straight line is somewhat exaggerated by the paucity of values in the midrange, due to lack of impregnated cells in the ventral "near-periphery" of the retina (cf. Fig. 1). The few values obtained in this range suggest that in ventral retina the curve of best fit is bowed. On the other hand, the values from dorsal cells, which encompass the total range of values, are better fitted to a straight line than is the population as a whole $(R=0.86)$. This result suggests, therefore, that pooling of data from different retinal locations has the potential of confounding tests for homogeneity and that, in this case, a more complex relationship exists between cell body and dendritic field size of starburst amacrine cells in rabbit retina. This is documented below ("Retinal nonuniformity of starburst amacrine cells"), where detailed examination of each parameter indivdually reveals that each varies as a complex function of linear distance across the retina (Figs. 7 and 8).

The difference in laminar position between type a and type b cells is obvious, but the cells appear grossly to constitute a single population in respect to the parameter of cell body size (Fig. 4), as well as in dendritic field size (Fig. 6) and branching pattern (Fig. 2), unless they are compared at precisely the same retinal location, as shown below ("Differences between type a and type b starburst amacrine cells"). As for tests of homogeneity it may be objected on theoretical grounds that no such test is wholely convincing, since two different classes of cells may be indistinguishable with reference to parameters 1 to $i$, but differ in an unrecognized parameter $j$.

Retinal nonuniformity of starburst amacrine cells. Both the cell bodies and the dendritic trees of starburst amacrine cells increase in size with distance from the region of central retina represented by the visual streak. This nonuniformity is not radially symmetrical, however. As explained under "Materials and Methods" ("Measurement and graphic reconstruction of starburst amacrine cells"), a one-dimensional determinant of position is sufficient to bring good order to the topographically dispersed data.

The cell body size of starburst amacrine cells varies little across the retina (Fig. 7), in comparison to the spectrum of retinal ganglion cell sizes (cf. Fig. $4 d$ ). In most of dorsal and ventral retina, average cell body diameter ranges from 10 to $11.5 \mu \mathrm{m}$. Sizes are smaller near the visual streak and smallest in the streak, ranging from 8.5 to $10 \mu \mathrm{m}$ in diameter. In dorsal retina, this decline begins in the region from 1.5 to $1.0 \mathrm{~mm}$ from the visual streak $(-1.5<d<-1.0)$, but data from ventral retina do not permit precise localization of this transitional zone which lies in the region $1>d>5$.

Of greater interest from a functional standpoint is the systematic change in dendritic field diameter of starburst amacrine cells with distance from the visual streak (Fig. 8). In contrast to the variation in size of cell bodies, variation in size of dendritic fields is conspicuous, both in terms of the greater range of variation in size and in differences between dorsal and ventral retina. The smallest size occurs at the mid-visual streak, where average dendritic field diameter is about $170 \mu \mathrm{m}$. The dorsoventral anisotropy in dendritic field diameters is evident when comparisons of size are made at equal dorsal and ventral distances. For instance, at $d=-5.5$, diameters are about 600 $\mu \mathrm{m}$, whereas at $d=+5.5$, they are about $400 \mu \mathrm{m}$. On the other 


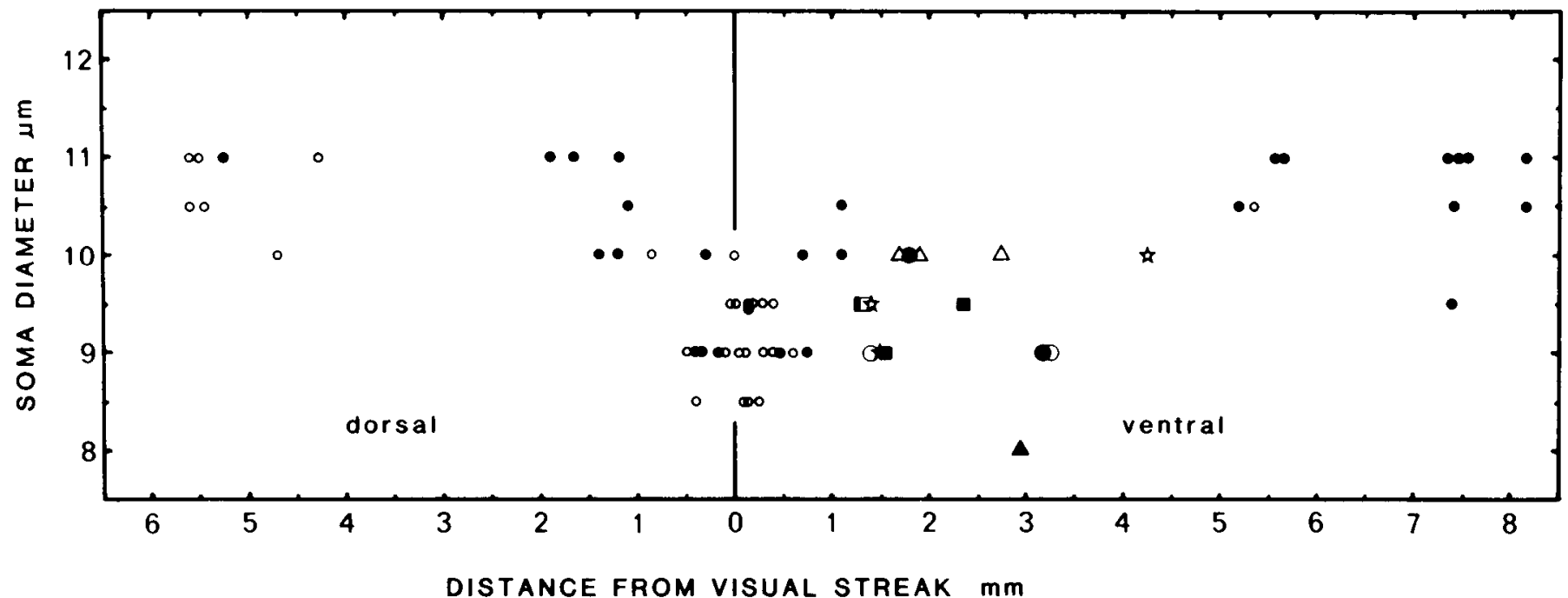

Figure 7. Starburst amacrine cells: Variation in cell body size. The ordinate shows average soma diameter; the abscissa shows dorsal and ventral distance perpendicular to the mid-visual streak $(d-0)$. Here and in Figure 8, small circles represent cells from retina of Figure 1; large symbols represent data from four Dutch Belted rabbit retinas (squares and triangles, two eyes from a single animal).

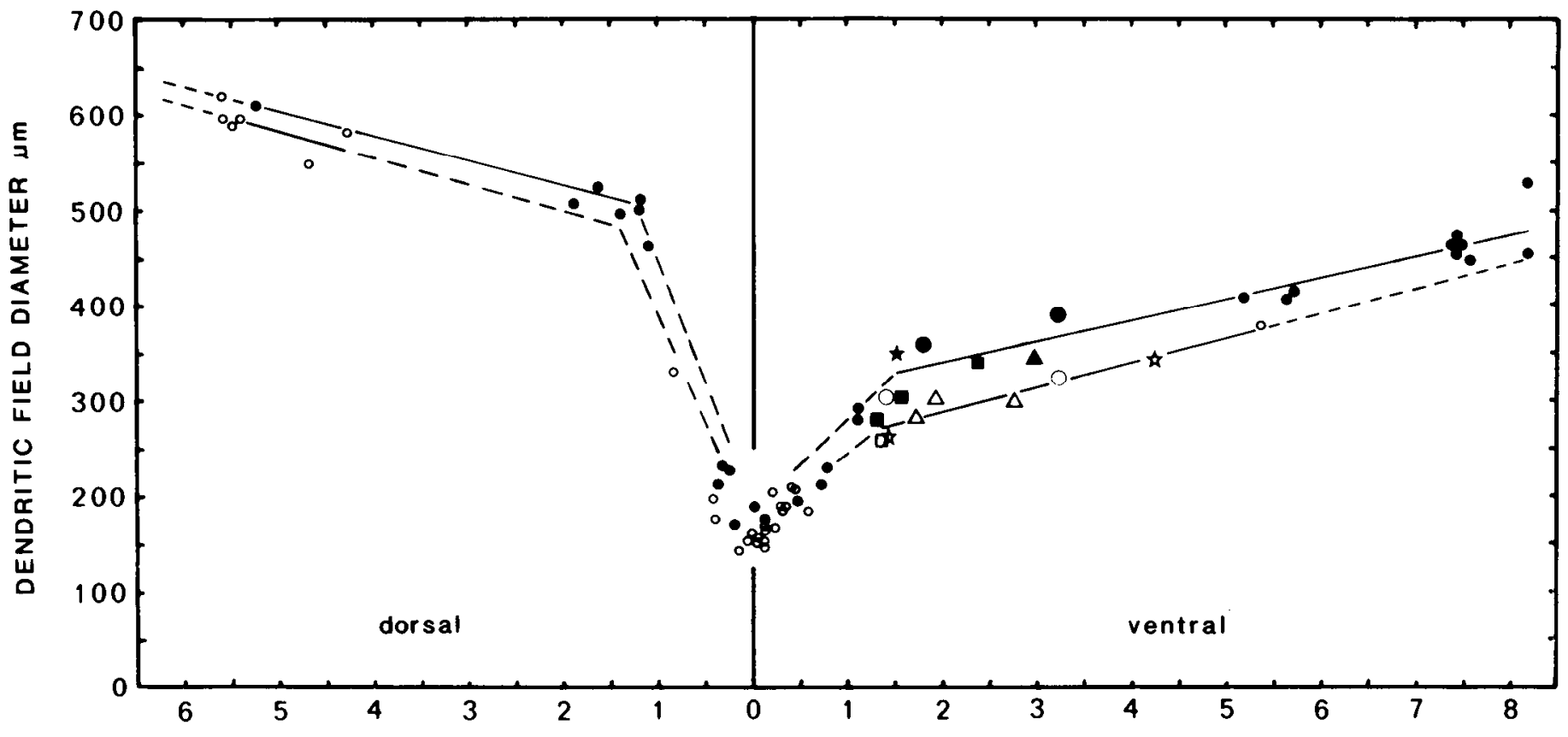

DISTANCE FROM VISUAL STREAK mm

Figure 8. Starburst amacrine cells: Systematic variation in dendritic field size. The ordinate shows average dendritic field diameter; the abscissa and symbols are as in Figure 7. Straight lines are fitted by the method of least squares (solid lines) separately to type a cells (solid symbols) and to type b cells (open symbols) of retina in Figure 1, and the lines are extrapolated (dashed lines). The fitted lines are also connected by dashed lines to $x, y=0.0,180$ and $0.0,160$, the respective minimum average diameters of type a and type $\mathrm{b}$ cells at the mid-visual streak. Six adjacent or overlapping type $a /$ type $b$ pairs from five retinas are included, and type a cells are consistently larger than type b cells.

hand, the slope of increase in field diameter at distances greater than $1.5 \mathrm{~mm}$ from the streak $(-1.5<d>1.5)$ is about the same in dorsal and ventral retina. The combined data from the five retinas obtained over the range $-5.6<\mathrm{d}<+8.3$ are well fitted by straight lines, when the region near the visual streak is treated separately from more peripheral retina, and when dorsal and ventral retina are treated separately, as in Figure 8.

Differences between type $a$ and type $b$ starburst amacrine cells. It is now well established that type a and type b starburst amacrine cells differ in the mirror-symmetrical disposition of their cell bodies and dendritic trees (Famiglietti and Siegfried, 1980; Famiglietti, 1981a, 1983a; see Fig. 9, $C$ and $D$ ). This is a categorical (nonparametric) difference between them. In flat view, however, type a and type b cells appear similar (cf. Fig. 2). Therefore, in order to evaluate relative differences between them, in those morphological features which vary continuously across the retina, close comparison is necessary. To make a convincing case, it is especially helpful to make use of those fortunate but rare instances when type a and type b starburst amacrine cells are found adjacent or overlapping in Golgi preparations. Where such comparisons can be made (e.g., Fig. $9 A$ ), type a cells and type b cells are found to differ quantitatively in a number of features, incuding: (1) dendritic field diameter, (2) segmental branching frequency distribution, (3) total number of branches, and (4) total number of boutons and appendages. 


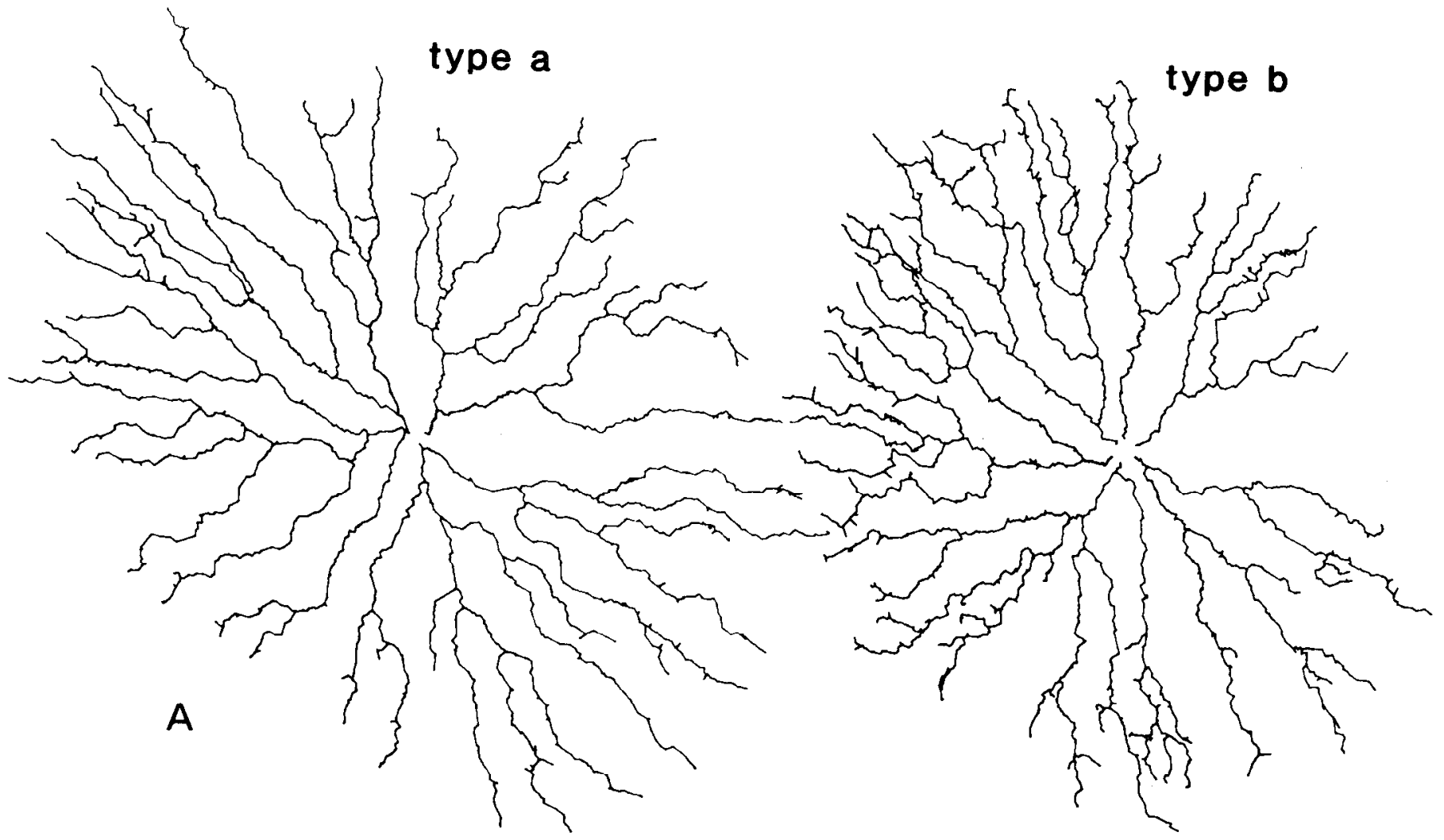

B

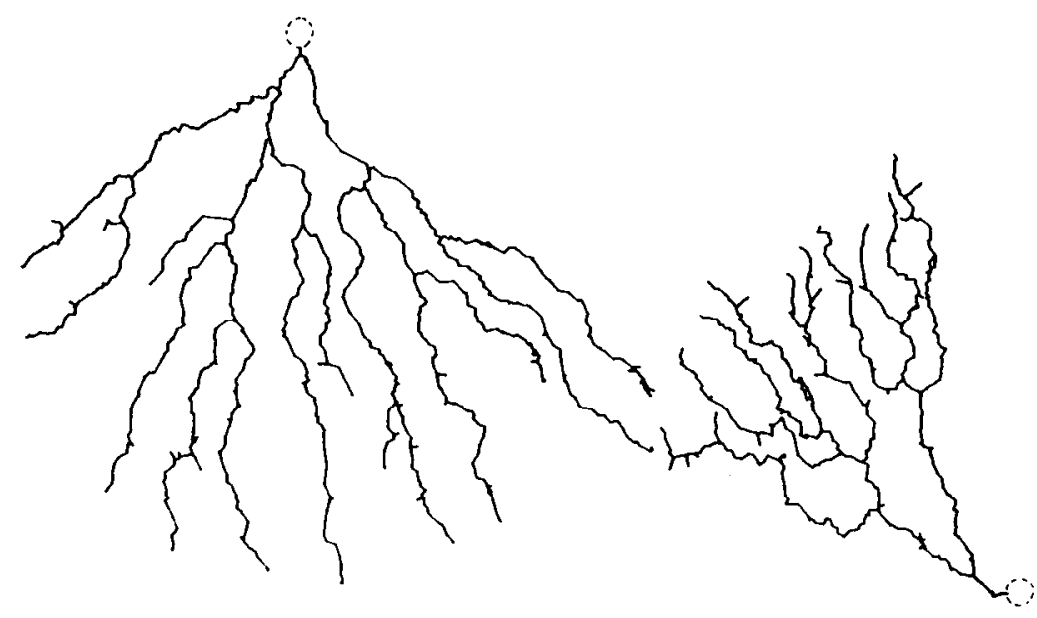

C

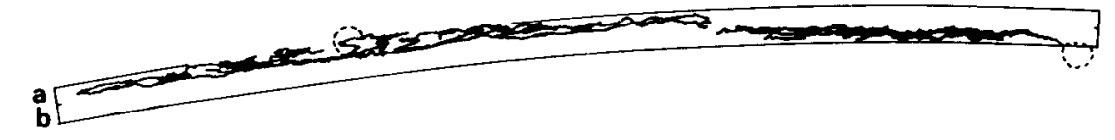

D

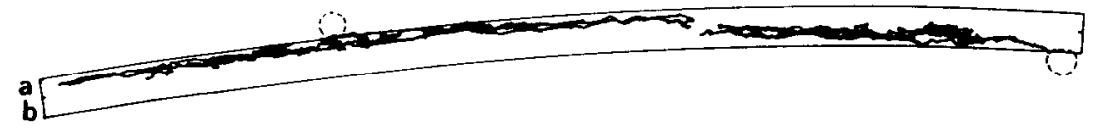


TABLE I

Starburst amacrine cells: Type a/type b pairs

\begin{tabular}{cccc}
\hline Retina No. & Type & $\begin{array}{c}\text { Field Diameter } \\
(D, \mu \mathrm{m})\end{array}$ & $\begin{array}{c}\text { Distance from } \\
\text { Streak } \\
(d, \mathrm{~mm})\end{array}$ \\
\hline R45R & $\mathrm{a}$ & 610 & -5.25 \\
& $\mathrm{~b}$ & 595 & -5.3 \\
R71L & $\mathrm{a}$ & 355 & +1.5 \\
& $\mathrm{~b}$ & 260 & +1.4 \\
R71R & $\mathrm{a}$ & 305 & +1.55 \\
& $\mathrm{~b}$ & 260 & +1.35 \\
R70R & $\mathrm{a}$ & 360 & +1.8 \\
& $\mathrm{~b}$ & 305 & +1.4 \\
R94L & $\mathrm{a}$ & 345 & +2.95 \\
& $\mathrm{~b}$ & 300 & +2.75 \\
R70R & $\mathrm{a}$ & 390 & +3.2 \\
& $\mathrm{~b}$ & 325 & +3.2 \\
\hline
\end{tabular}

In six pairs of adjacent or overlapping starburst amacrine cells examined in five retinas, from retinal locations $-5.3<\mathrm{d}$ $<3.2$, type a cells are all larger in dendritic field diameter than neighboring type b cells (Table I). In Figure 8, straight lines have been fitted by the method of least squares in ventral retina to 16 type a cells $(R=0.94)$ and 9 type b cells $(R=0.93)$, and in dorsal retina they have been fitted to 5 type a cells $(R=$ 0.98 ) and 6 type b cells $(R=0.68)$ outside the visual streak. In mid-visual streak, type a cells are on average $13 \%$ larger than type $b$ cells, but the maximum difference between them, measuring along the fitted lines, is at $d=1.5$, where type a cells are $18 \%$ larger than type b cells. The regression lines converge with increasing distance in ventral retina, and at $d=4.5$, where type a cells are $12 \%$ larger than type b cells, the difference in size between type a and type b cells reaches the limits of statistical significance ( $p=0.05, t$ test, $d f=23$ ) for this relatively small ventral sample of 25 cells.

Turning to parameters which describe dendritic branching pattern, one finds that the segmental branching frequency distributions of type $a$ and type $b$ starburst amacrine cells are shaped differently, reflecting higher branching frequency in the distal dendritic zone of type $b$ cells. The narrower terminal segment-frequency distributions of type a cells (Fig. 5, $a$ and $c)$, with peaks closer to those of preterminal distributions than those of type b cells (Fig. $5, b$ and $d$ ), indicate greater regularity of branching in type a cells as compared to type $b$ cells.

Finally, type b cells have more branches or dendritic segments, more boutons en passant in the distal dendritic zone, and more dendritic appendages than type a cells, when they are compared at the same retinal location. These appendages include spines without terminal expansions and pedunculated boutons terminaux. These subtle differences between type a and type $b$ starburst amacrine cells in the details of their dendritic branching may underly quantitative differences in their synaptic connections and, hence, physiological differences between ON and OFF pathways (see "Discussion").

Dendritic field overlap of starburst amacrine cells. Having established that the dendritic field diameter of starburst amacrine cells increases systematically with distance from the visual streak, one may ask whether or not the dendritic field overlap with neighboring cells increases as well. The answer to this question depends upon knowledge of the topographic density gradient of starburst amacrine cells and bears upon issues of developmental and physiological mechanisms in the retina raised in the "Discussion." If there is a decline in density which matches the increase in field diameter, then it is possible that dendritic field overlap remains constant. The simple mathematical expression governing the relevant variables is: $k(d)=$ $A(d) \cdot D(d)$, where $A$ is the dendritic field area of a single cell, and $D$ is the density of cell bodies at a specific distance, $d$, in millimeters, dorsal ( - ) or ventral $(+)$ to the visual streak. This is in essence the equation used by Fischer (1973) to calculate receptive field overlap of ganglion cells in cat retina. Provided with a source of $D(d)$, therefore, we can answer the question whether $k(d)=K$, a constant "factor of overlap" independent of $d$, for starburst amacrine cells, since we are already in possession of the determinants of $A(d)$ (Fig. 8).

There are two published sources from which the density values $D(d)$ may be derived. In one study the optic nerve was cut, the ganglion cells were allowed to degenerate, and the density of neurons remaining in the ganglion cell layer was determined in relationship to the visual streak (Masland, 1980). These values, in the range $-2<d<8.5$, are replotted in Figure $10 B$ (upper solid line). Since about $35 \%$ of the integral sum of neurons in the ganglion cell layer survive section of the optic nerve (Hayden et al., 1980; Masland, 1980), and since 20 to $30 \%$ of the cells in the normal ganglion cell layer are cholinergic amacrine cells (Masland and Mills, 1979; Hayden et al., 1980), between $57 \%$ and $86 \%$ of the neurons remaining after section of the optic nerve are taken to be the cholinergic/starburst amacrine cells. An intermediate value of $75 \%$ has been used to calculate topographic variation in density of starburst amacrine cells (Fig. 10B), and the remaining $25 \%$ are assumed to be other types of displaced amacrine cells which have been demonstrated in rabbit retina (Famiglietti and Siegfried, 1980; Famiglietti, 1981b).

Another source of density values, $D(d)$, for type b starburst amacrine cells is the study of Vaney et al. (1981), in which "matching" subsets of normally placed and displaced amacrine cells were stained with reduced silver methods, each subset forming a nonrandom mosaic of cell bodies at similar densities in peripheral retina. The selectivity of such "neurofibrillar" stains may be questioned, but this application of the method appears to stain starburst amacrine cells preferentially among amacrine cells. There is close agreement of these data with the estimate derived from the data of Masland (1980) over their common range (Fig. 10B), except at locations nearest the visual streak, where counts of "neurofibrillar" amacrines fall off (Vaney et al., 1981).

In Figure $10 \mathrm{~A}$, the dendritic field areas of 14 type b cells from dorsal and ventral retina (cf. Fig. 6) are plotted and regression lines fitted. The values of dendritic field overlap, $k(d)$, are calculated separately for the four sets of density values (Fig. $10 B)$, according to the equation $k(d)=A(d) \cdot D(d)$, and plotted in the line graph of Figure $10 C$. In the interval $1<d<5.5$, where the best data are available, it is fair to conclude that the conjecture $k(d)=K$ is approximately correct, and that the value of $K$ for type b starburst amacrine cells in this particular region of "near-peripheral" ventral retina, $k$, lies near 30 . It is not possible to assert that $k(d)=K$ for type b starburst amacrine cells everywhere in the retina. Nevertheless, based

Figure 9. Type a and type b starburst amacrine cells: Computer-aided graphic image analysis and quantitative comparison (cf. Tables I and II). These two cells are represented as triangles in Figures 7 and 8 at $d=2.95$ and 2.75 , respectively. $A$, The type a cell is larger in field size and is more regular in branching pattern, with fewer branches, spines, and boutons in the distal dendritic zone. Six terminal branches of the type a cell are slightly truncated at a retinal incisure above the letter $A$. $B$, To avoid the problem of retinal curvature in examination of stratification, one dendrite from each cell was selected for rotation. $C$, and $D$, Rotation of the image in $B$ around the $x$-axis at two angles, to show the narrowest dendritic stratification in the starburst "substratum" of sublamina $b(b)$, best seen in $C$, and in the substratum of sublamina a $(a)$, best seen in D. $z$-axis rotation $=37.5^{\circ}$. $x$-axis rotation $=83.5^{\circ}$ in $C$, and $82.5^{\circ}$ in $D$. Calibration $=50 \mu \mathrm{m}$. 


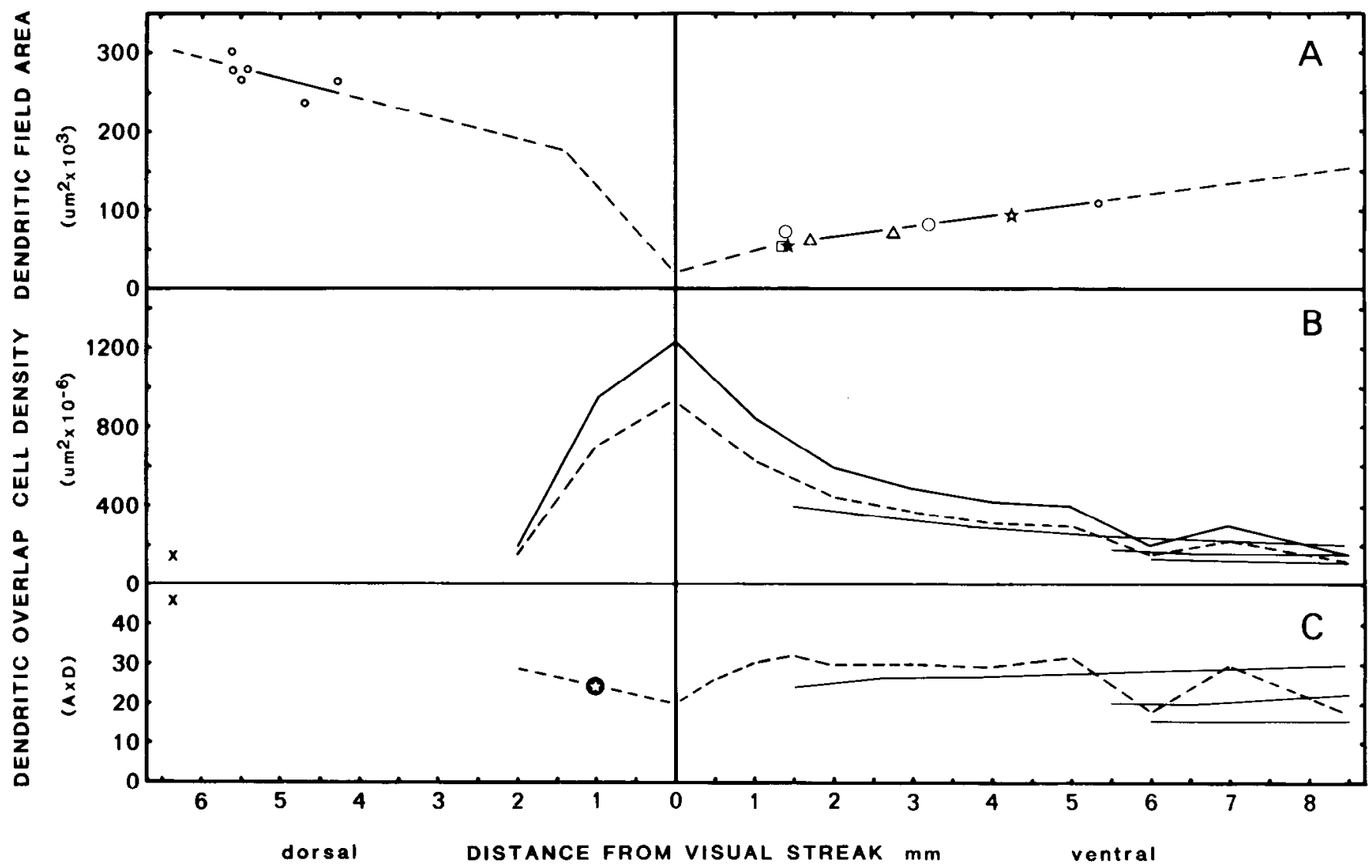

Figure 10. Dendritic field overlap of starburst amacrine cells. $A$, Calculated areas of 14 type b cells, 8 in ventral retina and 6 in dorsal retina. Fitted regression lines (solid lines) are extrapolated (dashed lines) in the ranges, $-6.5<d<-1.4$, and $1.3<\mathrm{d}<8.5$, with straight line extensions to $A(d)=20 \times 10^{3} \mu \mathrm{m}^{2}$, at $d=0 . B$, Density of putative type $\mathrm{b}$ starburst amacrine cells: $75 \%$ (dashed line) of all neurons remaining in the ganglion cell layer (upper solid line) after optic nerve section (Masland, 1980), and density of "displaced neurofibrillar amacrines" from three retinas (lower solid lines and $x$ ) (Vaney et al., 1981). C, Dendritic field overlap, $k(d)$, calculated separately for each set of density values; $k(d)$ is relatively constant $(28 \pm 2)$, in the range, $1<d<5$. The data base is less certain in other regions (see the text).

upon the data at hand, the view seems justified that dendritic field overlap varies across the retina by a factor less than 2 .

To illustrate the degree of dendritic field overlap calculated above for type b starburst amacrine cells, a computer-generated plot of overlap is presented in Figure $11 B$. This matrix of dendrites is obtained from the type $b$ starburst amacrine cell of Figure $11 \mathrm{~A}$, also illustrated in Figure 9 , by repeated plotting of the single dendritic tree with $k$ set equal to 28 .

A graphic representation of the dendritic field overlap of type a starburst amacrine cells has not been attempted here, since published density data pertaining to normally placed cells are insufficient. To judge from the data of Vaney et al. (1981), there is no appreciable difference in density between normally placed and displaced "neurofibrillar" amacrines for $d>8$. Extrapolation of the regression lines fitted to dendritic field diameters in Figure 6 suggests that at $d=8$, type a cells are only about $7 \%$ larger than type b cells. Nevertheless, if their densities are truly the same, then their dendritic field area, $A(d)$, and hence overlap, $k(d)$, at that location may exceed that of type b cells by about $12 \%$ (cf. Table II).

Another aspect of dendritic overlap, which reflects the apparent functional organization of starburst amacrine cells, pertains to the localization of presynaptic boutons in the distal dendritic zone. Since this zone constitutes 50 to $60 \%$ of the dendritic field area of starburst amacrine cells, the "effective overlap" of their dendritic trees, $k^{*}$, is only about half that calculated from the total dendritic field radius. If the dendritic field overlap of type a cells exceeds that of type b cells by 10 to $12 \%$, as suggested above, then the effective overlap of their distal dendritic zones would be correspondingly greater, as well. On the other hand, it has been demonstrated here for type $b$ cells that the numbers of terminal dendritic branches (Fig. 5) and of appendages and boutons en passant (Table II) are more numerous than those of adjacent type a cells (e.g., Fig 9). Thus, the actual coverage of the area by synaptic processes may be comparable for type a and type b cells at a given retinal location. Consequently, such dendritic "coverage" may be of more functional importance than simple dendritic overlap.

The "factor of areal coverage" or fractional coverage, $k_{a}(d)$, is described by the expression: $\mathrm{L}^{\prime} \cdot W \cdot D(d)$, where dendritic $L^{\prime}$ is total dendritic length including appendages, $W$ is the average dendritic width, estimated from concurrent electron microscopic studies, and $D(d)$ is the density of cells at a particular distance, $d$. An attempt has been made to represent this factor as well in the computer-generated plot of Figure $11 B$, by adjusting the plotting magnification so that the width of the pen-line is roughly equal to the average dendritic width. From the data presented in Table II, the calculated fractional coverage is $k_{a}(d)=0.63$. Thus were there not the superposition of lines in the plot of Figure $11 B$, which mimics the actual fasciculation of starburst dendrites (cf. Fig. $1 C$ ), about $63 \%$ of the area would be covered by dendrites. The "effective dendritic coverage" by dendritic branches in the distal dendritic zone, $k_{a}{ }^{*}$, would therefore be about $35 \%$.

The fractional volume occupied by this dendritic matrix and its surface area represent measurements still more pertinent to frequency of synapses made by starburst amacrine cells. Calculation of surface area based upon detailed light microscopic 

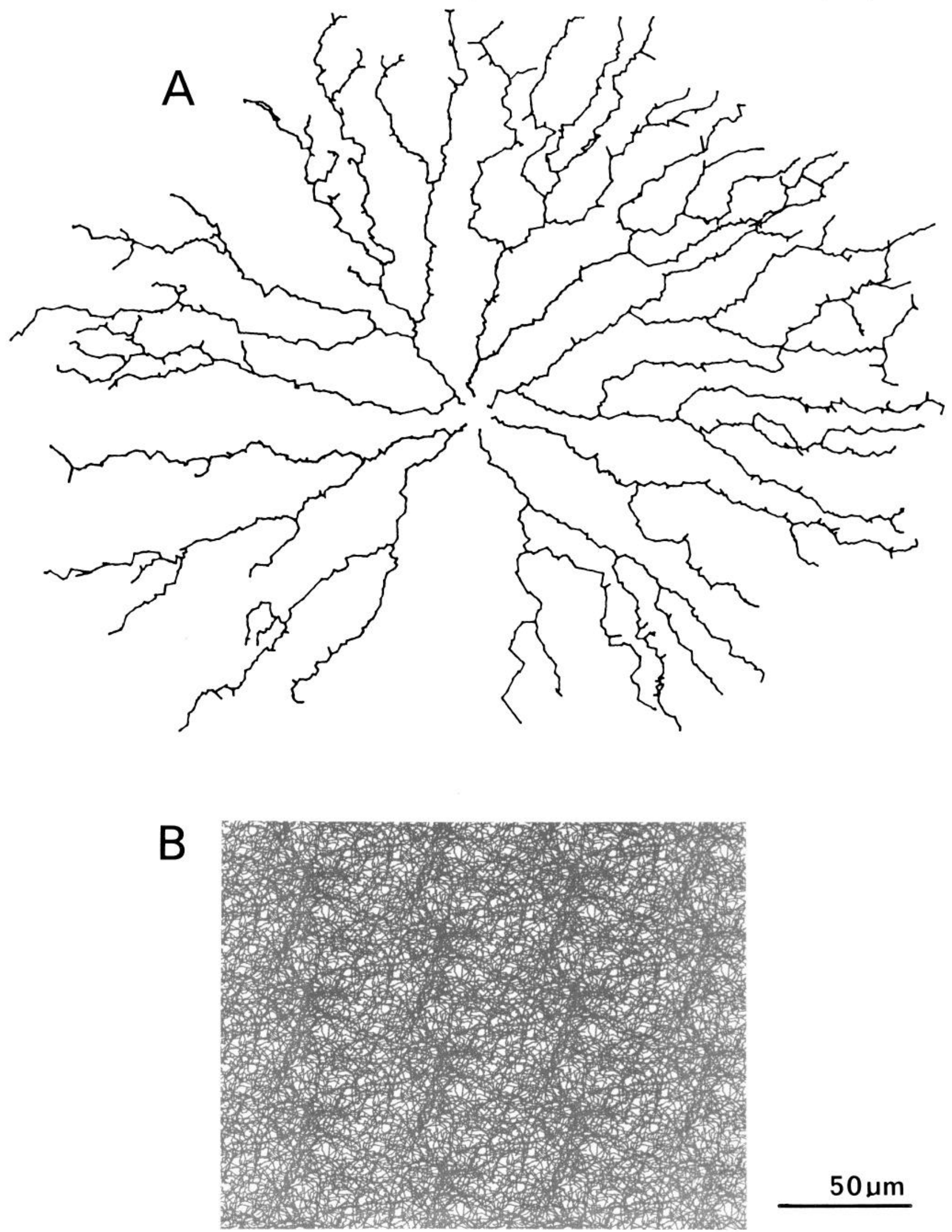

Figure 11. Areal dendritic coverage of starburst amacrine cells, computer-generated plot. $A$, The type b cell of Figure $9 A$ was chosen to exemplify type b cells at $d=2.75$, with a dendritic overlap, $k(d)=28$. B. The type b cell of $A$ is plotted repeatedly with cell body center displaced in a horizontally elongated hexagonal lattice. At the original magnification of the plot, the width of the pen line is about $0.35 \mu \mathrm{m}$. Fasciculation and superposition of dendrites mimic the actual case (cf. fig. 3c). Without superposition, areal dendritic coverage, $k_{u}(d)$, would be $63 \%$ (see Table II and text for explanations). 
TABLE II

Starburst amacrine cells of Figure 9: Morphometric comparison of the type $a$ and type $b$ cells

\begin{tabular}{|c|c|c|}
\hline & Type a & Type b \\
\hline \multicolumn{3}{|l|}{ A. Dendritic Length ${ }^{a}$} \\
\hline $\begin{array}{l}\text { 1. Total dendritic length (less appendages), } \\
L \text {, in } \mu \mathrm{m}\end{array}$ & $5778^{b}$ & 5416 \\
\hline 2. Total appendage length & 187 & 328 \\
\hline $\begin{array}{l}\text { 3. Total dendritic length (including ap- } \\
\text { pendages), } L^{\prime}\end{array}$ & 5965 & 5744 \\
\hline
\end{tabular}

B. Appendages and Boutons

1. Number of appendages

2. Number of boutons en passant

$161 \quad 199$

$193 \quad 239$

C. Dendritic Field Overlap

1. Distance from visual streak, $d$, in $\mathrm{mm}$ (Fig. 6)

2. Dendritic field area, $A(d)$, in $\mathrm{mm}^{2}$ (Fig. 10A)

3. Estimated density, ${ }^{\mathrm{c}} D(d)$, in $\mathrm{mm}^{-2}$ (Fig. 10B)

4. Dendritic field overlap, $k(d)=$ $A(d) \cdot D(d)$ (Fig. 10C)

5. Effective dendritic field overlap ${ }^{d}, \mathrm{k}^{*}(d)$ $=0.55 \mathrm{k}(d)$

D. Dendritic Field Coverage

1. Areal coverage: $k_{a}(d)=L^{\prime} \cdot W \cdot D(d)$ (estimated average dendritic width, $W$, is $0.30 \mu \mathrm{m}$; see the text)

2. Fractional volume: $k_{v}(d)=\pi \cdot L^{\prime} \cdot(W /$ $2)^{2} \cdot D(d) \cdot b^{-1}$ (estimated substratum unit volume, $b, 2.0 / 10^{-3} \mathrm{~mm}^{3}$; see the text)

${ }^{a}$ No shrinkage factor has been applied (see "Materials and Methods").

${ }^{b}$ Includes an estimated $230 \mu \mathrm{m}$ cut away from six terminal branches (Fig. 9A, lower left corner), when incising the retina.

${ }^{c}$ Data from Masland (1980) and Vaney et al. (1981). Values for type a cell were extrapolated: values of ${ }^{a} D(d)$ were available only at $d=8$ (Vaney et al., 1981$) ;{ }^{a} D(d=2.95)$ was calculated assuming ${ }^{a} k /{ }^{b} k$ is approximately constant.

${ }^{d}$ Sites of output to ganglion cells are boutons lying in the distal annular zone (Famiglietti, 1983b), which comprises 50 to $60 \%$ of the dendritic field area.

measurements has not been attempted, but an estimate of fractional volume, $k_{v}(d)$, can be made if a value can be chosen for the thickness or breadth, $b$, of the substratum which contains the dendritic trees of type b starburst amacrine cells: $k_{v}(d)=\pi \cdot L^{\prime} \cdot(W / 2)^{2} \cdot D(d) \cdot b^{-1}$. An accurate estimate of $b$ needs to be established in electron microscopic studies, but the best light microscopic estimate for $b$ is $2 \mu \mathrm{m}$ (cf. Fig. 9C). The fractional volume occupied by type $b$ starburst dendrites is thus calculated to be $7.4 \%$, while the "effective fractional volume" of boutons and preterminal segments is roughly $4 \%$. Similar calculations for the type a cell of Figure 9 yield similar results (Table II). Despite a seemingly small value, this percentage for the processes of type a or of type b cells must be considered exceptionally high, particularly when one realizes that a large fractional volume of the neuropil in the inner plexiform layer is occupied by glial processes.

\section{Discussion}

In a previous paper (Famiglietti, 1983a), the main morphological features of starburst amacrine cells were described, and a correlation was established between the cholinergic neurons demonstrated by Masland and Mills (1979) and starburst amacrine cells (Famiglietti and Siegfried, 1980; Famiglietti, 1981a, 1983a). In this paper, type a and type b starburst amacrine cells have been examined and characterized morphologically as two closely related populations of cells distributed across the retina. In general, these subpopulations are invariant with respect to those nonparametric features by which type a and type b cells have been defined as "types": level of dendritic branching and, secondarily, cell body position. Type a and type $\mathrm{b}$ cells are also constant in their overall branching patterns. In certain features best seen in flat view, such as dendritic field size and branching frequency, type $a$ and type b cells vary systematically across the retina, one type with the other. In central retina, however, one type differs subtly from the other in size and in branching pattern. Finally, calculations show that the degree of dendritic field overlap of starburst amacrine cells and the value of their "areal dendritic coverage" in the plane of the retina is exceptionally large.

Morphological constancy and systematic variation of starburst amacrine cells. The retina shares with other central nervous tissues many features of physiology, pharmacology, and metabolism. From a topographic standpoint, however, unlike most other neural tissues, it may exhibit a striking degree of histological nonuniformity, as it does in rabbit, in humans and in many other vertebrates which have anisotropic distributions of photoreceptors and ganglion cells. In contrast, histological uniformity is the rule in striate cortex, where one sort of spiny stellate cell is presumed to be histologically equivalent to another at some distance, even though it represents a far distant part of the visual field where receptive field size and magnification factor may be very different (Hubel and Wiesel, 1974). In a retina such as the cat's, ganglion cells of a given morphological class are smaller in cell body size and in dendritic field diameter at the center of the retina than they are at the retinal periphery (Boycott and Wässle, 1974; Famiglietti and Kolb, 1976), and their receptive field sizes are correspondingly smaller at the center, as well (Wiesel, 1960). If two physiological classes of ganglion cell can be regarded as functionally distinct across the retina (e.g., Enroth-Cugell and Robson, 1966), despite gradual parametric variation in size, shape, density, and some physiological measurements, then it can be predicted that there is both constancy and systematic variation across the retina in the presynaptic neurons which determine the characteristic response properties of such ganglion cells. Starburst amacrine cells, directly presynaptic to select classes of ganglion cells (Famiglietti, 1983b), are a histologically anisotropic population of presynaptic retinal neurons, which can be identified all across the retina, despite gradual variation in parameters giving rise to considerable differences in appearance at the extremes.

Starburst amacrine cells exhibit constancy in a number of morphological features, in addition to cell body position and level of dendritic branching in the IPL. These features pertain to branching pattern and distribution of boutons and are common to all starburst amacrine cells, regardless of their retinal location. In contrast, systematic variation does occur with distance from the visual streak: direct variation in size, and inverse variation in frequency of branches and boutons. The variation in cell body diameter is relatively small, but the variation in dendritic field size encompasses a 3- to 4 -fold increase in diameter and a greater than 12-fold increase in dendritic field area.

In the progression of dendritic field enlargement with distance, starburst amacrine cells gradually take on a less distinctive appearance, principally as a consequence of decreases in the frequencies per unit length of branching and boutons (e.g., Fig. 2, $A$ and $F$ ). The decline in frequency of boutons with distance from the visual streak cannot be an artifact, since the majority of these are boutons en passant, readily seen when 
present along the lengths of the dendrites. Given the example of starburst amacrine cells in rabbit retina, it is evident that a comprehensive identification of a unique population of amacrine cells may require that samples be obtained at several intervals across the retina without ignoring the covariation of other classes of amacrine cells. In this connection, one is bound to consider the confounding aspects of seemingly convergent morphology in identifying and classifying retinal neurons, for as the appearance of starburst amacrine cells becomes less distinctive in peripheral retina, so does the look of many other amacrine cells.

Cell body size of starburst amacrine cells. The size of amacrine cell bodies is small, relative to that of ganglion cells in most species, and difficult to measure accurately in Nissl-stained preparations; therefore, size has generally not been used as a major criterion in classifying amacrine cells, although classification of amacrine cells has been attempted in Nissl-stained material (Hughes and Vaney, 1980). In a Nissl study of rabbit ganglion cells, Oyster et al. (1981) stated that "small ganglion cells and displaced amacrine cells can have the same soma diameters," but these authors suggested that cell body shape and orientation of dendrites could be used to distinguish between them. In contrast, Golgi-impregnated starburst amacrine cells are always smaller than the smallest ganglion cells. Moreover, neither starburst amacrine cells nor other types of displaced amacrine cells in rabbit retina (Famiglietti, 1981b; E. V. Famiglietti, unpublished observations) can be distinguished from small ganglion cells based simply upon shape of cell body or disposition of primary dendrites. Despite differences in technique, the range in cell body size of starburst amacrine cells, 9 to $11 \mu \mathrm{m}$ in diameter, is consistent with that of radiolabeled cholinergic neurons in rabbit retina (Masland and Mills, 1979).

Differences between type $a$ and type $b$ starburst amacrine cells. The evidence of this study indicates that there are notable differences between type $a$ and type $b$ starburst amacrine cells in a region of retina extending from $1 \mathrm{~mm}$ dorsal to $6 \mathrm{~mm}$ ventral to the visual streak. This is a region in which the average dendritic field diameter of starburst amacrine cells is less than $500 \mu \mathrm{m}$. At the light microscopic level, the most obvious differences between type $a$ and type $b$ cells are those of dendritic field diameter $(a>b)$, and frequency of branching and boutons $(a<b)$. The size difference, which is the easiest to measure, is maximal not in the visual streak, but apparently $1.5 \mathrm{~mm}$ ventral to the streak. An explanation of this eccentric mismatch in the arrays of type a and type b starburst amacrine cells awaits studies of the "plate tectonics" of retinal layers during neuronal development and differentiation.

It is interesting that the differences in field size and branching, demonstrated here for the two types of starburst amacrine cells (cf. Fig. 9A), are exactly those exhibited by class I ganglion cells in the pericentral regions of cat retina (Famiglietti and Kolb, 1976, Figs. 1 and 2), where the type b (ON-center) ganglion cells are smaller and more "tufted" than type a (OFFcenter) cells at the same location. A similar distinction has been demonstrated for "ordinary" and "displaced" giant ganglion cells in dogfish retina (Stell and Witkovsky, 1973). Whether these common differences merely reflect similar processes of differential development or, in addition, a functional difference between $\mathrm{ON}$ and $\mathrm{OFF}$ pathways remains a topic for future investigations.

Dendritic field overlap and dendritic coverage of starburst amacrine cells. In order to simplify direct topographic comparisons of cat retina and visual cortex, Fischer (1973) proposed a mathematical transformation of the topographically anisotropic order of visual receptive field centers of retinal ganglion cells into an isotropic topography of field centers. This transformation was based upon the thesis that the product of ganglion cell density and receptive field center area, the "factor of overlap," is constant everywhere in the retina, a conclusion reached more recently for dendritic overlap of alpha ganglion cells in cat retina (Wässle et al., 1981). In rabbit retina, the overlap of similar ganglion cells is greater than in cat retina, and it is not clear that overlap is constant across the retina (Famiglietti and Siegfried, 1979; E. V. Famiglietti and E. C. Siegfried, unpublished observations).

As for the constancy of dendritic overlap of starburst amacrine cells in rabbit retina, we have been unable to arrive at a definite conclusion about the simplifying assumption of Fischer (1973). It does appear that there is a slight decrease in the factor of overlap in the visual streak, but density measurements in this region may be less reliable (cf. Oyster et al., 1981). In the limited region of ventral retina where reliable data are available, the factor of overlap is relatively constant. Whether or not there is constancy of overlap across the retina, the striking conclusion is that, for starburst amacrine cells, the absolute value of overlap is at least 10 times greater than that observed for ganglion cells in rabbit retina, and the "effective" dendritic field overlap of presynaptic boutons, $k^{*}>12$, is at least 5 times greater.

The "factor of dendritic overlap," $k$, although convenient and easily derived, is not fully adequate to describe dendritic coverage of the retina by a homogeneous population of neurons, because it is only a poor reflection of the dendritic surface area available to synaptic interaction with other cells. Thus, the "factor of areal dendritic coverage," $k_{a}$, has been calculated for starburst amacrine cells with a view to their functional role as cholinergic neurons presynpatic to ganglion cell dendrites. This factor of coverage, illustrated graphically in Figure 11, represents the two-dimensional dendritic silhoutte of an overlapping population of retinal neurons.

To illustrate the significance of the distinction between factors of overlap, $k$, and areal coverage, $k_{a}$, one may consider that the mismatch in factor of overlap, up to $12 \%\left({ }^{a} k>{ }^{b} k\right)$, is due to a difference in field area of more than $20 \%$, which is only partially compensated by a difference in density on the order of $6 \%$ (Fig. 8, Table II). Because the higher branching frequency of a type b cell compensates for its smaller size, however, values of $k_{a}$ (and surface area) may differ by as little as $3 \%\left({ }^{\mathrm{a}} k_{\mathrm{a}} \simeq{ }^{\mathrm{b}} k_{\mathrm{a}}\right.$ ). It is premature to suggest that $k_{a}$ is held constant across the retina, but considerations of aggregate dendritic surface area will be important in assessing synaptic interaction between starburst amacrine cells and postsynaptic ganglion cells.

Functional role of starburst amacrine cells in the retina. Since the dendritic field overlap of starburst amacrine cells is so great $\left(k>25 ; k^{*}>12\right)$, it cannot be thought simply to ensure the absence of gaps in the visual field representation, as proposed for some ganglion cells (e.g., Wässle et al., 1981). Although its meaning is not yet clear, an understanding of this "redundancy" of field representation must take into account the fact that, unlike retinal ganglion cells, the starburst amacrine cell releases neurotransmitter from its dendritic tree. Moreover, additional important clues are available. The $a / b$ sublaminar border of the IPL which separates the synaptic circuitry of OFF and ON cells, respectively, completely separates type a from type b starburst amacrine cells, both cell bodies and dendritic trees (Famiglietti, 1983a). Next, a high degree of dendritic overlap in a narrow substratum of each sublamina of the IPL offers high innervation density and thus the potential for selective control in limited regions of neuropil far smaller than those encompassed by a single dendritic tree. Finally, starburst amacrine cells are apparently cholinergic, hence, excitatory amacrine cells (cf. Masland and Mills, 1979). As a consequence, it is likely that these two networks serve to maintain a locally homogeneous level of excitation in select populations of ganglion cells (cf. Masland and Ames, 1976; Ariel and Daw, 1982a), 
in a manner dependent upon the separate activation of $\mathrm{ON}$ and OFF mechanisms.

In terms of cholinergic pharmacology, the exact functional role such selective excitation plays in the modulation of particular physiological types of ganglion cells remains enigmatic, despite careful study (Ariel and Daw, 1982a, b). Histological analysis directed at establishing the identity of the postsynaptic ganglion cells strongly implicates starburst amacrine cells in the mechanism of directional selectivity, a conclusion which finds limited support in available pharmacological data (Ariel and Daw, 1982b). This role, as well as a role in the less stimulusspecific activity of ganglion cells, is discussed elsewhere (Famiglietti, 1983b).

\section{References}

Ariel, M., and N. W. Daw (1982a) Effects of cholinergic drugs on receptive field properties of rabbit retinal ganglion cells. J. Physiol. (Lond.) 324: 135-160.

Ariel, M., and N. W. Daw (1982b) Pharmacological analysis of directionally sensitive rabbit retinal ganglion cells. J. Physiol. (Lond.) 324: 161-185.

Bloomfield, S. A., and R. F. Miller (1981) Functional stratification of $\mathrm{ON}$ and $\mathrm{OFF}$ pathways in the rabbit retina. Invest. Ophthalmol. 20 (Suppl.): 13.

Boycott, B. B., and H. Wässle (1974) The morphological types of ganglion cells of the domestic cat's retina. J. Physiol. (Lond.) 240: 397-419.

Chievitz, J. H. (1889) Untersuchungen über die Area centralis retinae. Arch. Anat. Physiol., pp. 139-196.

Davis, F. A. (1929) The anatomy and histology of the eye and orbit of the rabbit. Trans. Am. Ophthalmol. Soc. 27: 401-441.

Enroth-Cugell, C. and J. G. Robson (1966) The contrast sensitivity of retinal ganglion cells of the cat. J. Physiol. (Lond.) 269: 517-552.

Famiglietti, E. V., Jr. (1981a) Starburst amacrines: Two mirror-symmetrical retinal networks. Invest. Ophthalmol. 20 (Suppl.): 204.

Famiglietti, E. V., Jr. (1981b) Displaced amacrine cells of the retina. Soc. Neurosci. Abstr. 7: 620.

Famiglietti, E. V., Jr. (1983a) "Starburst" amacrine cells and cholinergic neurons: Mirror-symmetric $\mathrm{ON}$ and $\mathrm{OFF}$ amacrine cells of rabbit retina. Brain Res. 261: 138-144.

Famiglietti, E. V., Jr. (1983b) ON and OFF pathways through amacrine cells in mammalian retina: The synaptic connections of "starburst" amacrine cells. Vision Res. 23: 1265-1279.

Famiglietti, E. V., Jr., and H. Kolb (1976) Structural basis for ON- and OFF-center responses in retinal ganglion cells. Science 194: 193-195.

Famiglietti, E. V., Jr., and E. C. Siegfried (1979) Quantitative analysis of ganglion cells in rabbit retina. Invest. Ophthalmol. 18 (Suppl.): 84.

Famiglietti, E. V., Jr., and E. C. Siegfried (1980) The amacrine cells of rabbit retina. Invest. Ophthalmol. 19 (Suppl.): 70-71.
Famiglietti, E. V., Jr., A. Kaneko, and M. Tachibana (1977) Neuronal archilecture of $\mathrm{ON}$ and $\mathrm{OFF}$ pathways to ganglion cells in carp retina. Science 198: 1267-1268.

Fischer, B. (1973) Overlap of receptive field centers and representation of the visual field in the cat's optic tract. Vision Res. 13: 2113-2120.

Hayden, S. A., J. W. Mills, and R. H. Masland (1980) Acetylcholine synthesis by displaced amacrine cells. Science 210: 435-437.

Hubel, D. H., and T. N. Wiesel (1974) Uniformity of monkey striate cortex: A parallel relationship between field size, scatter, and magnification factor. J. Comp. Neurol. 158: 295-306.

Hughes, A. (1971) Topographic relationships between the anatomy and physiology of the rabbit visual system. Doc. Ophthalmol. 30: 33-159.

Hughes, A., and D. I. Vaney (1980) Coronate cells: Displaced amacrines of the rabbit retina? J. Comp. Neurol. 189: 169-190.

Masland, R. H. (1980) Acetylcholine in the retina. Neurochemistry 1: 501-518.

Masland, R. H., and A. Ames, III (1976) Responses to acetylcholine of ganglion cells in an isolated mammalian retina. J. Neurophysiol. 39. 1220-1235.

Masland, R. H., and J. W. Mills (1979) Autoradiographic identification of acetylcholine in the rabbit retina. J. Cell Biol. 83: 159-178.

Nelson, R., E. V. Famiglietti, Jr., and H. Kolb (1978) Intracellular staining reveals different levels of stratification for On- and Offcenter ganglion cells in cat retina. J. Neurophysiol. 41: 472-483.

Oyster, C. W., E. S. Takahashi, and D. C. Hurst (1981) Density, soma size and regional distribution of rabbit retinal ganglion cells. J. Neurosci. 1: 1331-1346.

Provis, J. M. (1979) The distribution and size of ganglion cells in the retina of the pigmented rabbit: A quantitative analysis. J. Comp. Neurol. 185: 121-138

Ramón-Moliner, E. (1962) An attempt at classifying nerve cells on the basis of their dendritic patterns. J. Comp. Neurol. 119: 211-227.

Slonaker, J. R. (1897) A comparalive study of the area of acute vision in vertebrates. J. Morphol, 13: 445-503.

Stell, W. K., and P. Witkovsky (1973) Retinal structure in the smooth dogfish, Mustelus canis: General description and light microscopy of giant ganglion cells. J. Comp. Neurol. 148: 1-32.

Stone, J. (1965) A quantitative analysis of the distribution of ganglion cells in the cat's retina. J. Comp. Neurol. 24: 337-352.

Vaney, D. I., L. Peichl, and B. B. Boycott (1981) Matching populations of amacrine cells in the inner nuclear and ganglion cell layers of the rabbit retina. J. Comp. Neurol. 199: 373-392.

Walls, G. L. (1942) The Vertebrate Eye and Its Adaptive Radiation, Cranbrook Press, Birmingham, MI.

Wann, D. F., T. A. Woolsey, M. L. Dierker, and W. M. Cowan (1973) An on-line digital-computer system for the semi-automatic analysis of Golgi-impregnated neurons. I. E. E. E. Trans. Biomed. Electron. 20: $233-248$.

Wässle, H., L. Peichl, and B. B. Boycott (1981) Dendritic territories of cat ganglion cells. Nature 292: 344-345.

Wiesel, T. N. (1960) Receptive fields of ganglion cells in the cat's retina. J. Physiol. (Lond.) 153: 583-594. 